\title{
The Search for Biomarkers in Alzheimer's Disease
}

\author{
Anna Meiliana ${ }^{1,2 *}$ and Andi Wijaya ${ }^{1,2 *}$ \\ 'Post Graduate Program in Clinical Biochemistry, Hasanuddin University, Makassar \\ ${ }^{2}$ Prodia Clinical Laboratory, Jakarta \\ *Address correspondence to this author at: Prodia Clinical Laboratory, Jl. Cisangkuy No.2, Bandung. \\ E-mail: anna_m@prodia.co.id, andi_w@prodia.co.id
}

\section{Abstract}

$\mathrm{B}$

ACKGROUND: As population demographic shift and the number of individuals with Alzheimer Disease $(\mathrm{AD})$ continue to increase, the challenge is to develop targeted, effective treatments and our ability to recognize early symptoms. In view of this, the need for specific $\mathrm{AD}$ biomarker is crucial.

CONTENT: In recent years it has become evident that CSF concentrations of some brain - specific proteins are related to underlying disease pathogenesis and may therefore aid clinical investigation. Among several, we have focused on three candidates that have been suggested to fulfil the requirements for biomarkers of $\mathrm{AD}: \beta$ - amyloid 42 (A $\beta 42)$, total Tau (T-tau) and tau phosphorylated at various epitopes (P-tau). An increasing number of studies suggest that supplementary use of these CSF markers, preferably in combination, adds to the accuracy of an AD diagnosis.

More recently visinin - like protein (VLP-1), a marker for neuronal cell injury has been studied. CSF VLP-1 concentrations were $50 \%$ higher in $\mathrm{AD}$ patients than in the control population.

SUMMARY: The number of studies aimed at the identification of new biomarkers for $\mathrm{AD}$ is expected to increase rapidly, not only because of the increasing insights into the pathological mechanisms underlying this disease, but also because new therapies have been developed or are under consideration now, which warrant an early and specific diagnosis for effective treatment of the patients.
KEYWORDS: Dementia, Amyloid Plaque, Neurofibrillary Tangels, Amyloid $\beta$-peptide 42 (A $\beta 42$ ), Total Tau (T-tau), Phosphorylated Tau (P-tau), visinin-like protein 1 (VLP-1).

\section{Introduction}

Alzheimer's disease is a progressive and fatal neurodegenerative disorder manifested by cognitive and memory deterioration, progressive impairment of activities of daily living, and a variety of neuropsychiatric symptoms and behavioral disturbances (1).

According to the World Health Organization, an estimated 37 million people worldwide currently have dementia; Alzheimer disease affects about 18 million of them (2). Increasing age is the greatest risk factor for Alzheimer disease. Its prevalence approximately doubles every five years after the age of 60 -one in 10 individuals over 65 years and nearly half of those over 85 are affected by the disease. So, although the incidence rate of Alzheimer disease is not thought to be changing, Alzheimer disease poses one of the greatest threats to the future of healthcare systems, owing to the anticipated demographic shift to an aging population - the number of people worldwide above the age of 60 years is expected to double over the next 25 years (3).

Alois Alzheimer first described plaques and tangles that characterize the diseased brain nearly 100 years ago. The dense tangles are a feature in many different dementias, but amyloid plaques in the brain are unique to Alzheimer 
disease (4). Thus the major hallmarks of Alzheimer disease are amyloid- $\beta(\mathrm{A} \beta)$-containing plaques, tau containing neurofibrillary tangles (NFTs) and progressive neuronal loss accompanied by cognitive decline. Although plaques and NFTs are pathognomic, it would be misleading to create the impression that these are the only significant pathological changes occurring in the $\mathrm{AD}$ brain. In fact, numerous other structural and functional alterations ensue, including inflammatory responses and oxidative stress (6-8). The combined consequences of all the pathological changes, including the effects of the $A \beta$ and tau pathologies, is severe neuronal and synaptic dysfunction and loss; at the time of death, the brain of a patient with $\mathrm{AD}$ may weigh one-third less than the brain of an age-matched, nondemented individual (9).

These figures underscore the urgency of seeking more effective therapeutic interventions for patients with Alzheimer's disease (1). Treatment requires accurate diagnosis and increasingly is based on an understanding of the pathophysiology of the disease (1).

The diagnosis of Alzheimer's disease is most often based on the criteria developed by the National Institute of Neurologic and Communicative Disorders and StrokeAlzheimer's Disease and Related Disorders Association (NINCDS-ADRDA) (10), according to which the diagnosis is classified as definite (clinical diagnosis with histologic confirmation), probable (typical clinical syndrome without histologic confirmation), or possible (atypical clinical features but no alternative diagnosis apparent; no histologic confirmation). Typical sensitivity and specificity values for the diagnosis of probable Alzheimer's disease with the use of these criteria are $65 \%$ and $75 \%$, respectively $(1,11)$.

Definitive diagnosis of Alzheimer disease can only be performed by examining the neuropathological features of the disease - amyloid plaques and neurofibrillary tanglesat autopsy. Nevertheless, in the day-to-day clinical setting, a variety of methods are used, and research has suggested that this can be considered $87 \%$ effective compared with autopsy. Early diagnosis is beneficial for the patients, as they can be treated early and any comorbidities can be monitored, as well as for their families, who can receive additional support $(3,12)$.

Recent research on CSF biomarkers has focused on early diagnosis, and several studies have shown a high predictive value for identification of prodromalAlzheimer's disease in mild cognitive impairment (MCI) (13). A large study with extensive clinical follow-up that assessed the ability of

CSF biomarkers to predict incipient Alzheimer's disease in MCI cases reported a sensitivity of $95 \%$ at a specificity of $83-87 \%$ for different combinations of biomarkers (14).

\section{Epidemiology and Risk Factors}

Alzheimer's disease is the most common form of dementia, accounting for $50-60 \%$ of all cases. The prevalence of dementia is below $1 \%$ in individuals aged $60-64$ years, but shows an almost exponential increase with age, so that in people aged 85 years or older the prevalence is between $24 \%$ and $33 \%$ in the Western world. Representative data from developing countries are sparse, but about $60 \%$ of patients with dementia are estimated to live in this part of the world. Alzheimer's disease is very common and thus is a major public health problem. In 2001, more than 24 million people had dementia, a number that is expected to double every 20 years up to 81 million in 2040 because of the anticipated increase in life expectancy. (15).

Besides aging, which is the most obvious risk factor for the disease, epidemiological studies have suggested several tentative associations. Some can be linked to a decreased reserve capacity of the brain, including reduced brain size, low educational and occupational attainment, low mental ability in early life, and reduced mental and physical activity during late life $(16,17)$. The brain reserve capacity is determined by the number of neurons and their synaptic and dendritic arborisation together with lifestyle-related cognitive strategies. A low reserve capacity has been linked with early presentation of some pathological changes of the disease (16). Moreover, several epidemiological studies have shown that head injury could be a risk factor (18). Whether brain trauma initiates the pathogenic cascade leading to plaque and tangle formation or whether it simply reduces the brain reserve capacity is unclear (33).

Other risk factors are associated with vascular disease, including hypercholesterolaemia, hypertension, atherosclerosis, coronary heart disease, smoking, obesity, and diabetes (16). Whether these are true causal risk factors for Alzheimer's disease, driving the pathogenic processes resulting in plaque and tangle formation, or whether they induce cerebrovascular pathology, which adds to clinically silent disease pathology thus exceeding the threshold for dementia, needs to be established. Some evidence suggests that dietary intake of homocysteine-related vitamins (vitamin B12 and folate); antioxidants, such as vitamin $\mathrm{C}$ and $\mathrm{E}$; unsaturated fatty acids; and also moderate alcohol intake, especially wine, could reduce the risk of Alzheimer's disease (19), but data so far are not conclusive to enable any general dietary recommendations to be made. Although environmental factors might increase the risk of sporadic Alzheimer's disease, this form of the disease has 
been shown to have a significant genetic background. A large population-based twin study showed that the extent of heritability for the sporadic disease is almost $80 \%$ (20).

Familial Alzheimer's disease is an autosomal dominant disorder with onset before age 65 years. The first mutation causing the familial form of the disease was identified in the amyloid precursor protein $(A P P)$ gene on chromosome 21 (21). When investigating other families with the familial disease, several additional $A P P$ mutations were found. However, these mutations explain only a few familial cases. Instead, mutations in the highly homologous presenilin 1 (PSEN1) and presenilin 2 (PSEN2) genes account for most cases of familial disease $(22,23)$. However, the familial form of the disease is rare, with a prevalence below $0.1 \%$ (24).

In 1993, two groups independently reported an association between the apolipoprotein $\mathrm{E}(A P O E) \varepsilon 4$ allele and Alzheimer's disease $(25,26)$. Meta-analysis shows that the $A P O E \& 4$ allele increases the risk of the disease by three times in heterozygotes and by 15 times in homozygotes (27). The APOE 84 allele operates mainly by modifying age of onset (28), with each allele copy lowering the age at onset by almost 10 years (25). The molecular mechanism for the disease-promoting effect has been difficult to pinpoint. ApoE acts as a cholesterol transporter in the brain with ApoE4 being less efficient than the other variants in reuse of membrane lipids and neuronal repair (29). On the other hand, $A p o E$ is essential for amyloid $\beta$ (A $\beta$ ) deposition, promoting $A \beta$ fibrillisation and plaque formation (30) possibly by acting as a pathological chaperone. The gene-dose dependent reduction in CSF A $\beta 42$ could be associated with this process (31). The APOE $\& 4$ allele has been calculated to account for most of the genetic risk in sporadic Alzheimer's disease (32).

\section{Molecular Pathogenesis}

Slowly but surely, Alzheimer's disease (AD) patients lose their memory and their cognitive abilities, and even their personalities may change dramatically. These changes are due to the progressive dysfunction and death of nerve cells that are responsible for the storage and processing of information. Although drugs can temporarily improve memory, at present there are no treatments that can stop or reverse the inexorable neurodegenerative process. But rapid progress towards understanding the cellular and molecular alterations that are responsible for the neuron's demise may soon help in developing effective preventative and therapeutic strategies (34).
Alzheimer's disease is the most common cause of dementia in the elderly. Extracellular amyloid plaques and intracellular neurofibrillary tangles are defining lesions in $\mathrm{AD}(33,35)$. Mounting genetic and biochemical data support the hypothesis that amyloid- $\beta$ (A $\beta$ ) accumulation and aggregation in the brain are early and central events in the pathogenesis of $\mathrm{AD}(33,36) . \mathrm{A} \beta$ is derived from sequential proteolytic processing of amyloid precursor protein $(A P P)$ by $\beta$ - and $\gamma$-secretases. Mutations associated with early-onset familial $\mathrm{AD}(\mathrm{FAD})$ are dominantly inherited and are found in the APP gene itself or in the presenilin 1 (PSEN1) and PSEN2 genes, the products of which, together with nicastrin, APH1 and PSENEN2, are essential components of a protein complex that is responsible for $\gamma$-secretase activity (37). A common feature of most FAD mutations is that they increase the generation of $A \beta$ peptides or increase the proportion of the longer $\mathrm{A} \beta 42 \mathrm{form}$, which has a higher tendency to aggregate and is more toxic than the shorter $A \beta 40$ form (36). Because $\gamma$-secretase cleavage of a number of substrates is important for synaptic function and neuronal survival, a loss-of-function hypothesis for PSEN mutations in $\mathrm{AD}$ pathogenesis has also been proposed (38).

One hundred years after Alois Alzheimer's description of the plaques and tangles in the first reported case of Alzheimer disease, we have looked at the proteins that make up these deposits as pathologies and have not extensively investigated their physiologic roles. Perhaps we should consider the possibility that $\mathrm{A} \beta$ has a function that relates directly to its involvement in vascular pathology (39). We know, for example, that APP is involved in blood clotting (40) and that $A \beta$ drains from the brain along the walls of the microvasculature (41). Perhaps we should consider the possibility that $A \beta$ has complementary damage-response roles: (i) as an emergency sealant of the vasculature during hemorrhage and (ii) as a neuronal depressant (42).

The aggregates of amyloid $\beta$-peptide $(A \beta)$ in the brain parenchyma (amyloid plaques) also in the walls of small brain arteries, leading to cerebral amyloid angiopathy (CAA). The degree of amyloid deposition ranges from a thin ring of amyloid in the vessel wall to large plaquelike extrusions into the brain parenchyma. CAA is also associated with localloss of neurons, synaptic abnormalities, microglial activation and microhaemorrhage. Clearly, such defects will alter neuronal and synaptic function and even at its earliest stage, amyloid deposits around brain vessels could certainly interfere with the dynamic adaptation of cerebral blood flow (CBF) to changing brain function (23).

Bell et al. provide a molecular mechanism that could explain how vascular defects may lead to reduced amyloid 
clearance, and thus Alzheimer's pathology, by showing that hypoxia in vascular smooth muscle cells (VSMCs) of meningeal arterioles induces transcription factors that regulate the expression of the low-density lipoprotein receptor related protein 1 (44), a major efflux transporter for $A \beta$ across the blood brain barrier (45).

Alterations in the microcirculation precede the appearance of amyloid plaque deposits and is followed by cognitive deficits (46), indicating that an excess of $A \beta$ could lead to CAA through direct perturbation of amyloid clearance by VSMCs. The study by Bell et al.(44) provides a molecular model that explains how a general and quite common circulatory problem may lead to failure of an essential brain detoxification process (that is, the removal of $A \beta$ from the brain. Their findings also strengthen the vascular hypothesis of $A D$, showing how vascular defects may underlie the occurrence of sporadic $\mathrm{AD}$ (47-49).

Cerebrovascular disease and Alzheimer disease are common diseases of aging and frequently coexist in the same brain. Accumulating evidence suggests that the presence of brain infarction, including silent infarction, influences the course of Alzheimer disease. Conversely, there is evidence that $\beta$-amyloid can impair blood vessel function. Vascular $\beta$-amyloid deposition, also known as CAA, is associated with vascular dysfunction in animal and human studies. Alzheimer disease is associated with morphological changes in capillary networks, and soluble $\beta$-amyloid produces abnormal vascular responses to physiological and pharmacological stimuli (50).

\section{APP Processing and A $\beta$ Generation}

Brain regions involved in learning and memory processes, including the temporal and frontal lobes, are reduced in size in $\mathrm{AD}$ patients as the result of degeneration of synapses and death of neurons. Central to the disease is altered proteolytic processing of the amyloid precursor protein (APP) resulting in the production and aggregation of neurotoxic forms of $A \beta$. Neurons that degenerate in $\mathrm{AD}$ exhibit increased oxidative damage, impaired energy metabolism and perturbed cellular calcium homeostasis; $\mathrm{A} \beta$ appears to be an important instigator of these abnormalities (34).

APP is an integral membrane protein with a single membrane-spanning domain, a large extracellular glycosylated $\mathrm{N}$ terminus and a shorter cytoplasmic $\mathrm{C}$ terminus $-A \beta$ is located at the cell surface (or on the lumenal side of ER and Golgi membranes), with part of the peptide embedded in the membrane.

The normal functions of APP are not fully understood, but increasing evidence suggests it has important roles in regulating neuronal survival, neurite outgrowth, synaptic plasticity and cell adhesion (51). APP is transported along axons to presynaptic terminals where it accumulates at relatively high levels, which can result in $\mathrm{A} \beta$ deposition at synapses. One possible function of full-length APP is as a cell surface receptor that transduces signals within the cell in response to an extracellular ligand (52). Physiological roles for $\operatorname{sAPP} \alpha$ are supported by data showing that sAPP $\alpha$ is released from presynaptic terminals in response to electrical activity, and that $\operatorname{sAPP} \alpha$ regulates neuronal excitability and enhances synaptic plasticity and learning and memory, possibly by activating a cell surface receptor that modulates the activity of potassium channels and also activates the transcription factor NF-k $\beta$ (53).

Synapses may be particularly susceptible to the adverse effects of aggregating forms of $A \beta$, as is suggested by the ability of $A \beta$ to impair synaptic ion and glucose transporters and by electrophysiological studies showing that $A \beta$ impairs synaptic plasticity $(51,54)$. A $\beta$ may damage neurons by inducing oxidative stress and disrupting cellular calcium homeostasis (51). Coincident with the increased production of $A \beta$ in $A D$ is a decrease in the amount of sAPP $\alpha$ produced, which may contribute to the demise of neurons because SAPP $\alpha$ is known to increase the resistance of neurons to oxidative and metabolic insults (51)

Synapses are likely to be the sites at which neuronal death is initiated in $\mathrm{AD}$ because they contain most of the biochemical machinery for the initiation and execution of apoptosis, and $A \beta$ can induce apoptotic cascades in synapses (55).

The amyloid- $\beta(A \beta)$ peptide is derived via proteolysis fromalargerprecursormolecule called the amyloid precursor protein (APP), a type 1 transmembrane protein consisting of 695-770 amino acids. APP can undergo proteolytic processing by one of two pathways. Most is processed through the nonamyloidogenic pathway, which precludes A $\beta$ formation. The first enzymatic cleavage is mediated by $\alpha$-secretase, of which three putative candidates belonging to the family of a disintegrin and metalloprotease (ADAM) have been identified: ADAM9, ADAM10 and ADAM17. Cleavage by $\alpha$-secretase occurs within the $A \beta$ domain, thereby preventing the generation and release of the $A \beta$ peptide. Two fragments are released, the larger ectodomain $(\mathrm{SAPP} \alpha)$ and the smaller carboxy-terminal fragment (C83). Furthermore, C 83 can also undergo an additional cleavage mediated by $\gamma$-secretase to generate P3. APP molecules that are not cleaved by the non-amyloidogenic pathway become a substrate for $\beta$-secretase ( $\beta$-site APP-cleaving 
enzyme 1 ; BACE1), releasing an ectodomain ( $\mathrm{APP} \beta)$, and retaining the last 99 amino acids of APP (known as C99) within the membrane. The first amino acid of C99 is the first amino acid of A $\beta$. C99 is subsequently cleaved $38-43$ amino acids from the amino terminus to release $A \beta$, by the $\gamma$-secretase complex, which is made up of presenilin 1 or 2 , nicastrin, anterior pharynx defective and presenilin enhancer 2 . This cleavage predominantly produces $A \beta 1-$ 40 , and the more amyloidogenic $A \beta 1-42$ at a ratio of $10: 1$ $(9,56,57)$.

The toxicity associated with accumulation of $A \beta$ suggests that activation of endoproteolytic enzymes capable of preventing generation of $\mathrm{A} \beta$ might provide a realistic target for pharmacotherapy of Alzheimer disease. On the other hand, cleavage of APP by $\beta$ - and $\gamma$-secretase generates $\mathrm{A} \beta$ peptides. $\beta$-secretase, which initiates cleavage of APP, cuts the protein at the $\mathrm{N}$ terminus and has been successfully cloned. $\gamma$-secretase is the second enzyme that cleaves APP, and full understanding of its mechanism of action has long been lacking. Reconstitution of $\gamma$-secretase activity illuminates the interaction between the various protein components of the $\gamma$-secretase complex that leads to formation of $\mathrm{A} \beta$ (58).
Either presenilin-1 (PS1) or presenilin-2 (PS2) makes up the first component of the $\gamma$-secretase complex. Mutations in the genes that encode PS1 and PS2 cause a subset of early-onset, familial Alzheimer disease. Presenilin mutations probably act upstream of APP or tau to cause Alzheimer disease pathology, including deposition of $A \beta$ and accumulation of hyperphosphorylated tau. For example, mutant presenilins have been shown to increase formation of the longer $A \beta$ species, $A \beta 42$. This species is important for Alzheimer disease pathology because it accelerates deposition of $A \beta$, which presumably precipitates earlyonset Alzheimer disease. Thus, disease-related mutations in presenilin are considered to shift cleavage of APP by $\gamma$-secretase toward increased $A \beta 42$ production (53).

In fact, presenilin is a part of a large, high-molecularweight complex with $\gamma$-secretase activity. Nicastrin, the product of a recently cloned gene, is a component of this $\gamma$-secretase complex (59). Overexpressing the two genes together, however, does not ramp up $\gamma$-secretase activity (60). Instead, other proteins are required. Studies of Notch signaling in C. elegans, which depends on $\gamma$-secretase activity (61), provide additional information about $\gamma$-secretase activity. Aph-1 and PEN-2 are two

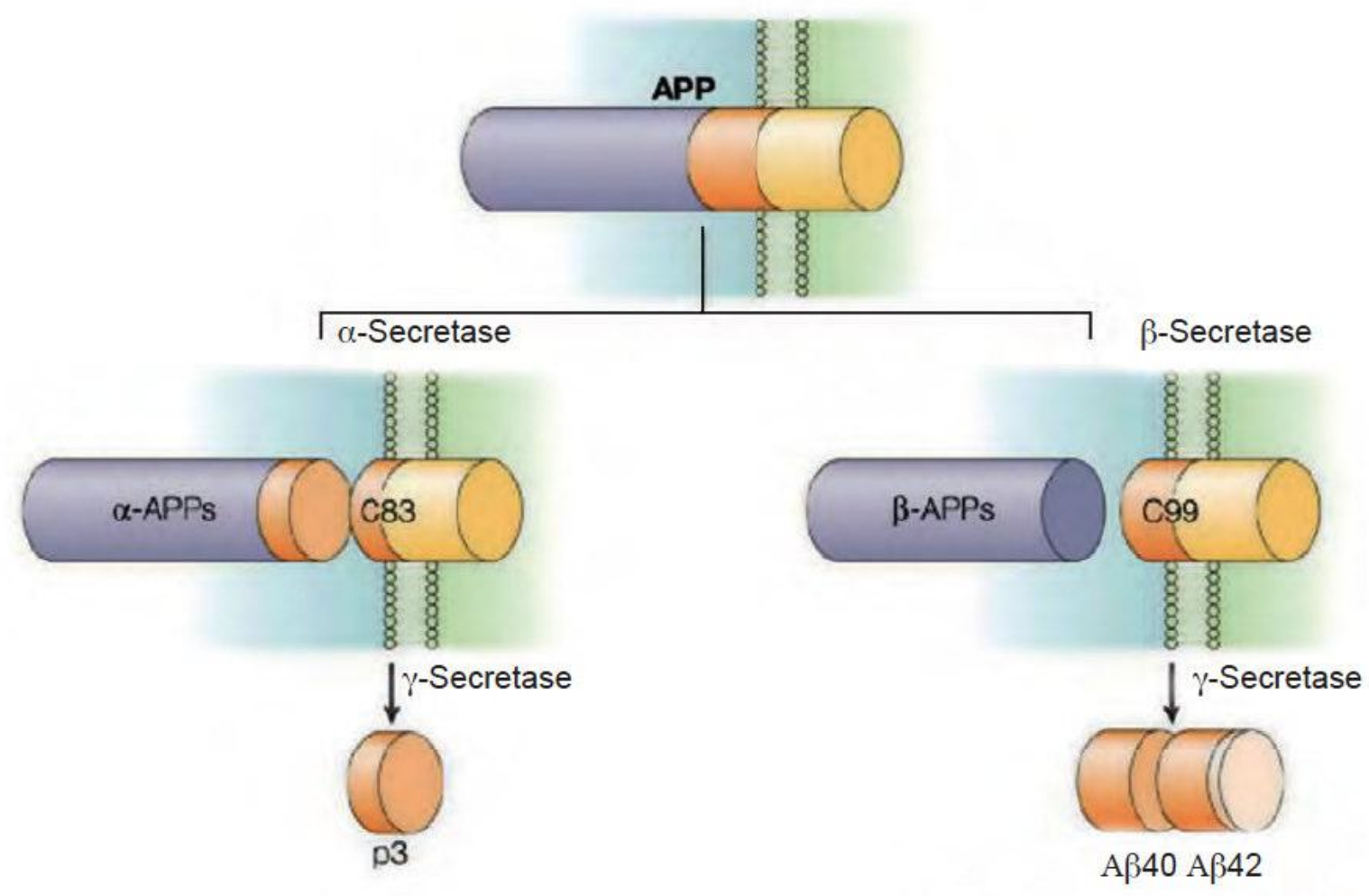

Nature Reviews | Neuroscience

Figure 1. Amyloid - precursor protein (APP) and its metabolites (Adapted with permission from Nature Publishing Groups). 
transmembrane proteins that are expressed upstream of release of the Notch intracellular domain $(62,63)$. When these proteins are knocked down, $\gamma$-secretase activity decreases, which suggests that these two proteins may also be involved in $\gamma$-secretase activity $(62,64)$.

The results described above indicate that four proteins (presenilin, nicastrin, Aph-1 and PEN-2) are required for $\gamma$-secretase activity, but none of them generate $\gamma$-secretase activity on their own; an increase in activity is only possible when the four proteins are overexpressed together $(58,64)$. Thus, it is clear that these four proteins are essential components needed for $\gamma$-secretase activity (65).

Fahihi et al. (66) report that expression of the noncoding antisense RNA for BACE1-which is the rate limiting enzyme in $A \beta$ synthesis - is elevated in the brains of individuals with Alzheimer's disease. BACE1 antisense RNA increases $A \beta$ production by stabilizing the $B A C E 1$ $\mathrm{mRNA}$ and results in increased $\mathrm{BACE} 1$ protein expression and activity. $A \beta$ in turn subtly induces the expression of this antisense RNA. In vitro, at least, this induction sets up a feed forward mechanism, which reiteratively accelerates $\mathrm{A} \beta$ production and then $\mathrm{BACE} 1$ expression. If the same holds true in vivo, this feed-forward could theoretically cause an ever accelerating tempo of disease (67).

\section{Tau Phosphorylation and NFT}

The accumulation of proteinacious fibrillary substances (such as senile plaques (SPs) made of $\beta$-amyloid (A $\beta$ ), or neurofibrillary tangles (NFTs) made of tau), but significant circumstantial evidence also clearly implicates these aggregates in the onset and progression of most agingrelated neurodegenerative disorders that manifest clinically with progressive cognitive and/or motor impairments. In the case of neurodegenerative tauopathies - a group of disorders that includes Alzheimer's disease (AD) and the frontotemporal dementias (FTDs) - NFTs consisting of aggregated straight or paired helical filaments (SFs and PHFs, respectively), twisted ribbons or other conformations (68) of aberrantly phosphorylated forms of the microtubuleassociated protein (MAP) tau are the diagnostic hallmark lesions in the CNS (69). It is increasingly evident that tau-mediated neurodegeneration may result from the combination of toxic gains-of-function acquired by the aggregates or their precursors and the detrimental effects that arise from the loss of the normal function(s) of tau in the disease state.
The primary function of the MAP tau, which is particularly abundant in the axons of neurons, is to stabilize MTs. There are six major isoforms of tau expressed in the adult human brain, all of which are derived from a single gene by alternative splicing. From a structural stand-point, tau is characterized by the presence of a MT-binding domain, which is composed of repeats of a highly conserved tubulin binding motif (70) and which comprises the carboxyterminal (C-terminal) half of the protein, followed by a basic proline-rich region and an acidic amino-terminal (N-terminal) region, which is normally referred to as the 'projection domain'.

Interestingly, although the primary function of the MT-binding domain of tau is the stabilization of MTs, various lines of investigation have indicated that it may also engage with other structures and enzymes, including RNA (71) and presenilin 1 (PS1) (72). Similarly, numerous possible binding partners have been proposed for both the proline-rich and the projection domains (the $\mathrm{SH} 3$ domains of src-family tyrosine kinases such as FYN, and the plasma membrane $(74,75)$, respectively). Collectively these findings support the notion that tau might be a rather promiscuous binder that is prone to heterogeneous interactions - particularly when disengaged from the MT - which may lead to protein misfolding and aggregation (76).

Under pathological conditions, the equilibrium of tau binding to the MTs is perturbed, resulting in an abnormal increase in the levels of the free (unbound) tau fraction. It is likely that the resultant higher cytosolic concentrations of tau increase the chances of pathogenic conformational changes that in turn lead to the aggregation and fibrillization of tau (76).

Under physiological conditions, single tau molecules are typically phosphorylatedat a subset of potential phosphate-acceptor amino-acid residues. During late stage neurodegeneration, the phosphorylation state of a single tau molecule can reach such high levels that many or most of these residues are phosphorylated and, at the same time, a higher proportion of tau molecules are in this hyperphosphorylated state. Although several kinases have been found to be capable of phosphorylating tau in vitro, it is not yet clear whether all of them participate in tau phosphorylation under physiological or pathological conditions in vivol. Nonetheless, glycogen synthase kinase 3 (GSK3), cyclin-dependent kinase 5 (CDK5) and the microtubule-affinity-regulating kinase (MARK) have received particular attention as potential targets for diseasemodifying therapies using inhibitory compounds (77). 
The overall effect of the increased rate and/or state of phosphorylation appears to be the abnormal disengagement of tau from the MTs. Furthermore, it is likely that various other pathological events, including $A \beta$-mediated toxicity, as well as oxidative stress and inflammation, may be able to trigger or contribute (independently or in combination) to an abnormal detachment of tau from the MTs (78-81). As described above, in $\mathrm{AD}$ and related neurodegenerative disorders that are collectively referred to as tauopathies $(82,83)$, tau no longer binds to the MTs; instead it becomes sequestered into NFTs in neurons, and into glial tangles in astrocytes or oligodendroglia (69).

The discovery that the total level of NFTs correlates with the degree of cognitive impairment $(85,86)$ provided the initial circumstantial evidence to suggest that toxic gains-of-function by NFTs might play an important part in then progression of the disease.

\section{Mitochondrial Dysfunction and Oxidative Stress}

Many lines of evidence suggest that mitochondria have a central role in aging-related neurodegenerative diseases. Mitochondria are critical regulators of cell death, a key feature of neurodegeneration. Mutations in mitochondrial DNA and oxidative stress both contribute to aging, which is the greatest risk factor for neurodegenerative diseases. In all major examples of these diseases there is strong evidence that mitochondrial dysfunction occurs early and acts causally in disease pathogenesis (87).

There is extensive literature supporting a role for mitochondrial dysfunction and oxidative damage in the pathogenesis of $\mathrm{AD}$. Oxidative damage occurs early in the $\mathrm{AD}$ brain, before the onset of significant plaque pathology (88). Oxidative damage also precedes $A \beta$ deposition in transgenic APP mice (89), with upregulation of genes relating to mitochondrial metabolism and apoptosis occurring even earlier and co-localizing the neurons undergoing oxidative damage (90). Moreover, such oxidative damage and mitochondrial dysfunction probably contribute causally to $\mathrm{AD}$-related pathology.

Several pathways connecting oxidative stress and $\mathrm{AD}$ pathology have recently been uncovered. Oxidative stress may activate signaling pathways that alter APP or tau processing. For example, oxidative stress increases the expression of $\beta$-secretase through activation of c-Jun aminoterminal kinase and p38 mitogen-activated protein kinase (MAPK) (91), and increases aberrant tau phosphorylation by activation of glycogen synthase kinase 3 (92). Oxidantinduced inactivation of critical molecules may also be important. In a proteomic study, the prolyl isomerase PIN1 was found to be particularly sensitive to oxidative damage (93). PIN1 catalyses protein conformational changes that affect both APP and tau processing.

Functional complexes with $\gamma$-secretase activity, which is essential to cleave APP and create amyloid- $\beta$, have been found in mitochondria (94). Insulin degrading enzyme (IDE), which is important for amyloid- $\beta$ removal, can be targeted to mitochondria by alternative translation initiation (95). The presequence peptidase PreP, which is localized to the mitochondrial matrix and is responsible for degrading presequences and other short peptides, can also degrade amyloid- $\beta$ (96).

The calcium overload of mitochondria results in the opening of the mitochondrial permeability transition pore (mPTP) (97), a large channel in the inner mitochondrial membrane. Its opening allows uncontrolled bidirectional passage of large molecules, which results in the functional and structural disintegration of mitochondria - akin to an activation of a natural self destruction facility built into the complicated mitochondrial fabric (98).

Park et al report that NADPH oxidase, the major source of free radicals in blood vessels, is responsible for the cerebrovascular dysregulation induced by $\mathrm{A} \beta$. Thus, the free-radical production and the associated alterations in vasoregulation induced by $A \beta$ are abrogated by the NADPH oxidase peptide inhibitor gp91ds-tat and are not observed in mice lacking the catalytic subunit of NADPHoxidase (gp91phox). Furthermore, oxidative stress and cerebrovascular dysfunction do not occur in transgenic mice overexpressing the amyloid precursor protein but lacking gp9lphox. The mechanisms by which NADPH oxidase-derived radicals mediate the cerebrovascular dysfunction involve reduced bioavailability of nitric oxide. Thus, a gp91phox-containing NADPH oxidase is the critical link between $A \beta$ and cerebrovascular dysfunction, which may underlie the alteration in cerebral blood flow regulation observed in $\mathrm{AD}$ patients (99).

Finally, several recent reports suggest that many of the proteins implicated in $\mathrm{AD}$ pathogenesis have direct physical involvement with mitochondria or mitochondrial proteins (87).

\section{Inflammation}

In addition to $A \beta$ deposition, neurofibrillary tangle 
accumulation, and neuronal loss, the end-stage pathology of $\mathrm{AD}$ is also notable for the presence of numerous cellular and molecular markers of an inflammatory response that are often associated with the $\mathrm{A} \beta$ deposits (100). The cellular inflammatory response consists of widespread astrogliosis and microgliosis. A large number of molecular markers of inflammation are also increased, including multiple cytokines, interleukins, other acute-phase proteins, and complement components. A $\beta$ aggregates appear capable of inciting an inflammatory response, and there is evidence that inflammation can promote increased $\mathrm{A} \beta$ production and also enhance $A \beta$ deposition (100). Thus, an A $\beta$ induced inflammatory response could promote further $A \beta$ accumulation and increased inflammation. Alternatively, it is possible that under certain circumstances the inflammatory response is beneficial and may actually promote $\mathrm{A} \beta$ clearance (101).

Inflammation clearly occurs in pathologically vulnerable regions of the $\mathrm{AD}$ brain, and it does so with the full complexity of local peripheral inflammatory responses. In the periphery, degenerating tissue and the deposition of highly insoluble abnormal materials are classical stimulants of inflammation (100).

Tesseur et al. report that the expression of TGF- $\beta$ type II receptor (T $\beta R I I)$ by neurons is reduced very early in the course of $\mathrm{AD}$ and that reduced TGF- $\beta$ signaling increased $\mathrm{A} \beta$ deposition and neurodegeneration in a mouse model of $\mathrm{AD}$ (102). Thus, reduced T $\beta$ RII levels indicate a likely dysfunction in TGF- $\beta$-mediated neuroprotective signaling events in the $A D$ brain. Reduced TGF- $\beta$ signaling, therefore, may lead to neurotrophic factor deficiencies and thus neuronal dysfunction (103).

It has been hypothesized that neurodegeneration results from a chronic inflammatory response to deposited amyloid $(100,104)$. Alternatively, the various forms of $A \beta$ aggregates may be directly neurotoxic $(105,106)$.

\section{Cholesterol Metabolism in the Brain}

Emerging from the established genetic dispositions of $\mathrm{AD}$ is an association between plasma cholesterol and AD $(107,108)$. Retrospective analysis of the effect of cholesterol lowering HMG-CoA reductase inhibitors (statins) on plasma cholesterol levels and coronary heart disease suggests that statins significantly reduce $\mathrm{AD}$ development. One study of 57,104 patients over 60 years of age who were taking lovastatin or pravastatin showed a $60-73 \%$ lower incidence of AD (109). Another study concluded that individuals 50 years and older who were treated with statins had a substantially lower risk of developing dementia, independent of the presence or absence of hyperlipidemia (110). These suggestive clinical observations correlate with in vivo and in vitro evidence, indicating a role for cholesterol in APP processing and A $\beta$ generation (111).

Consistent with the in vivo observations, plasma membrane cholesterol levels modulate APP processing by the $\alpha$-secretase pathway in vitro (112). Treatment of neuronal and nonneuronal cell lines with either cholesterolextracting agents or with statins dramatically increased $\alpha$-secretase activity and the release of the neurotrophic APPs $\alpha$ fragment, and concomitantly decreased $\beta$-secretase activity. Moreover, cellular sites with increased APPs $\alpha$ production were membrane regions with low cholesterol concentrations and high fluidity. Statin-induced reduction of cellular cholesterol levels resulted in reduced generation of $A \beta-42$ and $A \beta-40$ both in vitro and in vivo (113). Collectively, these studies support a role for cellular cholesterol in modulating $A \beta$ production.

The mechanism by which cholesterol modulates the proteolytic cleavage of APP is unclear. However, the effect of cholesterol on membrane fluidity is potentially important. As first suggested by in vitro studies, increased plasma membrane fluidity may enhance APP $/ \alpha$-secretase interactions and $\alpha$-secretase enzymatic activity (112). In contrast, rigid cholesterol-enriched membranes may reduce APP $/ \alpha$-secretase interactions and promote $\beta$ - and $\gamma$-secretase processing (113). In support of this suggestion, $\gamma$-secretase activity has been identified in cholesteroland sphingolipidrich membrane microdomains known as lipid rafts $(113,114)$. Lipid rafts appear to promote the accumulation of $A \beta$ and may initiate $A \beta$ aggregation (115).

Intriguingly, apolipoprotein $\mathrm{J}$, which is also secreted by glia and is believed to be a major carrier of amyloid- $\beta$ peptides in biological fluids (116), was transported efficiently across the BBB in an Loco - density lipoprotein Receptor - Related Protein 2 (LRP2) -dependent manner. Furthermore, complexing amyloid- $\beta 42$ to apolipoprotein J enhanced amyloid- $\beta 42$ clearance rates by $83 \%$ (117). This important study shows that various transport pathways are required to clear amyloid- $\beta$ from the brain, and highlights the quantitative and temporal contribution of apolipoprotein E, apolipoprotein J, LRP1 and LRP2 in mediating amyloid- $\beta$ efflux across the BBB .

Several studies have suggested that high intracellular cholesterol concentrations increase the amyloidogenic processing of amyloid precursor protein (APP), leading 
to greater amyloid- $\beta$ production $(114,118-120)$. On the other hand, low cellular cholesterol levels have been associated with reduced amyloid- $\beta$ generation $(112,121$ 125). Interestingly, APP and all of the components of secretases (the enzymes that cleave APP), are integral membrane proteins. Furthermore, the proteolytic activity of $\gamma$-secretase takes place within the hydrophobic membrane environment (125). These observations suggest that the ABCA and ABCG classes of the ATP-binding cassette transporter superfamily, which modulate intracellular cholesterol trafficking and homeostasis, may play a key role in amyloid- $\beta$ metabolism (126).

The brain contains about $2 \%$ of the total body cholesterol, of which most is unesterified. It is found in the plasma membranes of glial cells, which provide structural and metabolic support to neurons, in neuronal membranes, and in the myelin sheaths that insulate and protect neurons. Under normal conditions, essentially all of the cholesterol in the brain is synthesized locally (127). The bloodbrain barrier prevents any real contribution from plasma lipoproteins. Thus, mechanisms that remove cholesterol from the brain are required for cholesterol homeostasis.

To be transported across the blood-brain barrier, most cholesterol is thought to be converted to 24(S)hydroxycholesterol, a soluble oxysterol that can diffuse across the barrier, enter the blood circulation, and be taken up directly by the liver for excretion $(128,129)$. The enzyme suggested to perform this conversion is cholesterol 24-hydroxylase or Cyp46, a new sub-family member of the cytochrome P450 enzymes. Cyp46 is highly expressed in the brain (130) and is expressed in neurons in the cerebral cortex, hippocampus, and dentate gyrus (131) (the same neurons that are preferentially targeted in $\mathrm{AD}$ ).

Most of the 24-hydroxycholesterol in circulation originates from the brain (131). Since neurodegeneration involves degradation of neuronal cell membranes and release of cholesterol, the relationship of plasma concentrations of this oxysterol to brain cholesterol metabolism was examined. In a study comparing $\mathrm{AD}$ subjects with healthy age-matched controls, depressed subjects, and subjects with vascular dementia not related to $\mathrm{AD}$, the plasma levels of 24-hydroxycholesterol were significantly elevated only in subjects with $\mathrm{AD}$ or vascular dementia (132). Another study showed increased 24hydroxycholesterol levels in the CSF of AD subjects (133). These results suggest that neuronal death is coupled with increased flux of cholesterol from the brain. In addition, 24-hydroxycholesterol is neurotoxic and may directly contribute to neurodegeneration (134). However, 24hydroxycholesterol concentrations are decreased in cases of advanced $\mathrm{AD}$ (135). In a recent study, three statins (lovastatin, simvastatin, and pravastatin) and niacin reduced plasma concentrations of 24-hydroxycholesterol in $\mathrm{AD}$ subjects (136).

\section{Adipoprotein E and Its Receptor}

The vast majority of $\mathrm{AD}$ cases are late-onset $(\mathrm{LOAD})$ and their development is probably influenced by both genetic and environmental risk factors. A strong genetic risk factor for late-onset $\mathrm{AD}$ is the presence of the $\varepsilon 4$ allele of the apolipoprotein $\mathrm{E}(A P O E)$ gene, which encodes a protein with crucial roles in cholesterol metabolism. There is mounting evidence that APOE4 contributes to $\mathrm{AD}$ pathogenesis by modulating the metabolism and aggregation of amyloid- $\beta$ peptide and by directly regulating brain lipid metabolism and synaptic functions through APOE receptors. Emerging knowledge of the contribution of APOE to the pathophysiology of $\mathrm{AD}$ presents new opportunities for $\mathrm{AD}$ therapy.

It is widely believed that impaired $A \beta$ clearance is a major pathogenic event for LOAD. A $\beta$ has a relatively short half-life in the brain. Using in vivo microdialysis and a $\gamma$-secretase inhibitor, it has been shown that $A \beta$ has a half-life of $\sim 2 \mathrm{~h}$ and $\sim 4 \mathrm{~h}$ in young and aged mice, respectively (138). In human brains the $A \beta$ clearance rate is $8.3 \%$ per hour (139), indicating that $A \beta$ is actively and efficiently cleared from the brain.

There are two major pathways by which $A \beta$ is cleared from the brain: receptor-mediated clearance by cells in the brain parenchyma (microglia, astrocytes and neurons), along the interstitial fluid drainage pathway or through the bloodbrain barrier (BBB); and through endopeptidase-mediated proteolytic degradation. Receptor-mediated clearance of $A \beta$ in the brain is likely to be mediated by the APOE receptors LRP1, LDLR and VLDLR, which are widely expressed in neurons, astrocytes and microglia of the brain parenchyma, as well as in endothelial cells, astrocytes and smooth muscle cells at the BBB and cerebral arteries. APOE as well as LRP1 and several other LRP1 ligands (for example, $\alpha 2$-macroglobulin and lactoferrin) are present in amyloid plaques. These receptors can bind $\mathrm{A} \beta$ directly (141) or indirectly through $A \beta$ chaperones. APOE is the best characterized $A \beta$ chaperone. APOE immunoreactivity is found in amyloid plaques $(140,142)$, suggesting that APOE interacts with $A \beta$ directly in $A D$ brains.

APOE is a major apolipoprotein and a cholesterol carrier in the brain8. In humans, the APOE gene exists as three different polymorphic alleles ( $\varepsilon 2, \varepsilon 3$ and $\varepsilon 4)$, 
which engender six different genotypes ( $\varepsilon 2 / \varepsilon 2, \varepsilon 2 / \varepsilon 3, \varepsilon 2 /$ $\varepsilon 4, \varepsilon 3 / \varepsilon 3, \varepsilon 3 / \varepsilon 4$ and $\varepsilon 4 / \varepsilon 4) . \varepsilon 3$ is the most (77\%) and $\varepsilon 2$ the least ( $8 \%$ ) common allele 8 . The $\varepsilon 4$ allele frequency is $-15 \%$ in general populations but is $\square 40 \%$ in patients with $\mathrm{AD}$. Individuals with one $\varepsilon 4$ allele are three to four times as likely to develop $\mathrm{AD}$ than those without $\varepsilon 4$ alleles $(25,144)$. This odds ratio is much greater than those for other $\mathrm{AD}$ risk alleles, which are typically $<1.5$ (144). The effects of the $\varepsilon 4$ allele on $\mathrm{AD}$ risk are maximal between 60 and 70 years of age, and the prevalence of the 84 allele in $\mathrm{AD}$ patients is $>50 \%$. Interestingly, the rare $\varepsilon 2$ allele is associated with protection against LOAD compared with the $\varepsilon 3$ allele (25).

APOE3-lipoprotein binds to A $\beta$ with higher affinity than APOE4-lipoprotein (146). Accordingly, APOE3 clears $A \beta$ through APOE receptors on the cell surface more efficiently than APOE4. Indeed, several studies using different amyloid mouse models expressing either human APOE3 or human APOE4 demonstrated that APOE3-expressing mice develop fewer amyloid plaques than APOE4-expressing mice $(30,147,148)$. Post-mortem studies have demonstrated increased amyloid plaque load in the brains of carriers of the $\varepsilon 4$ allele for both sporadic (149) and genetic $\mathrm{AD}$ cases (150), and this notion has been confirmed by positron emission tomography imaging studies from 'cognitively normal' controls (151). An emerging body of data has identified multiple pathways that could explain the pathogenic nature of APOE4. These include $\mathrm{A} \beta$ production, $\mathrm{A} \beta$ clearance, $\mathrm{A} \beta$ fibrillization, tangle formation, cholesterol homeostasis, synaptic plasticity and repair, and neuronal toxicity

\section{Neuronal Cell Death}

Neurodegenerative diseases such as Alzheimer's disease and Parkinson's disease trigger neuronal cell death through endogenous suicide pathways. Surprisingly, although the cell death itself may occur relatively late in the course of the degenerative process, the mediators of the underlying cell-death pathways have shown promise as potential therapeutic targets (152).

Neurodegenerative diseases are associated with a number of insults that may trigger PCD: misfolded proteins, reactive oxygen and nitrogen species, mitochondrialcomplex inhibition, calcium entry, excitotoxicity, trophicfactor withdrawal, and death-receptor activation to name a few. In some cases, however, deaths occur that do not fit neatly into any of the three classes of PCD, and these more controversial forms of death are also discussed below (152).

The biochemical activation of classical apoptosis occurs through two main pathways. These are the extrinsic pathway, which originates through the activation of cellsurface death receptors such as Fas, and results in the activation of caspase- 8 or -10 (153), and the intrinsic pathway, which originates from mitochondrial release of cytochrome $\mathrm{c}$ and associated activation of caspase-9. A third, less well-characterized pathway - essentially a second intrinsic pathway - originates from the endoplasmic reticulum (ER) and also results in the activation of caspase-9 (154-156). Other organelles, such as the nucleus and Golgi apparatus, have damage sensors that link to apoptotic pathways (158).

Autophagy (referring to macroautophagy herein) is an intracellular process that allows cells to engulf cytoplasmic contents - both soluble molecules and large organelles - in specialized double membranes and deliver them to lysosomes for degradation (158). This self-eating process is often a nonselective stress response to many extracellular and intracellular stimuli. Autophagy is highly dynamic and involves multiple steps, including the initial formation of double membranes and autophagosomes and their maturation into autolysosomes. Whether autophagosomes are beneficial or detrimental to a cell depends on the context (159).

The amyloid $\beta(A \beta)$ peptide is thought to be a major culprit in $\mathrm{AD}$, and its production and degradation have been intensely investigated. Nevertheless, it remains largely unknown how $\mathrm{A} \beta$ pathology is modulated by the autophagy pathway. The study by Pickford and colleagues shows that beclin 1 , a multifunctional protein that also plays an important role in the autophagy pathway, affects some aspects of $A \beta$ pathology in aged but not young transgenic mice expressing amyloid precursor protein (APP). These findings further support the notion that modulation of autophagy, in this case through beclin 1 , may represent a novel therapeutic strategy for AD (159).

The novel data of Grimm et al (160) suggest that the amyloid and associated neurodegenerative pathologies of $\mathrm{AD}$ result from a self-amplifying cascade of membraneassociated events (Fig. 2). Altered $\gamma$-secretase activity, resulting from mutations in APP or presenilin and/or oxidative stress, increases the $A \beta 42 / A \beta 40$ ratio which, in turn, increases SMase and HMG-CoA reductase activities. As a consequence, levels of ceramides and cholesterol are increased and levels of sphingomyelin are decreased in the membranes of neurons. These alterations may then promote further production of $A \beta 42$. $A \beta 42$-induced membrane-associated oxidative stress and changes in lipid 


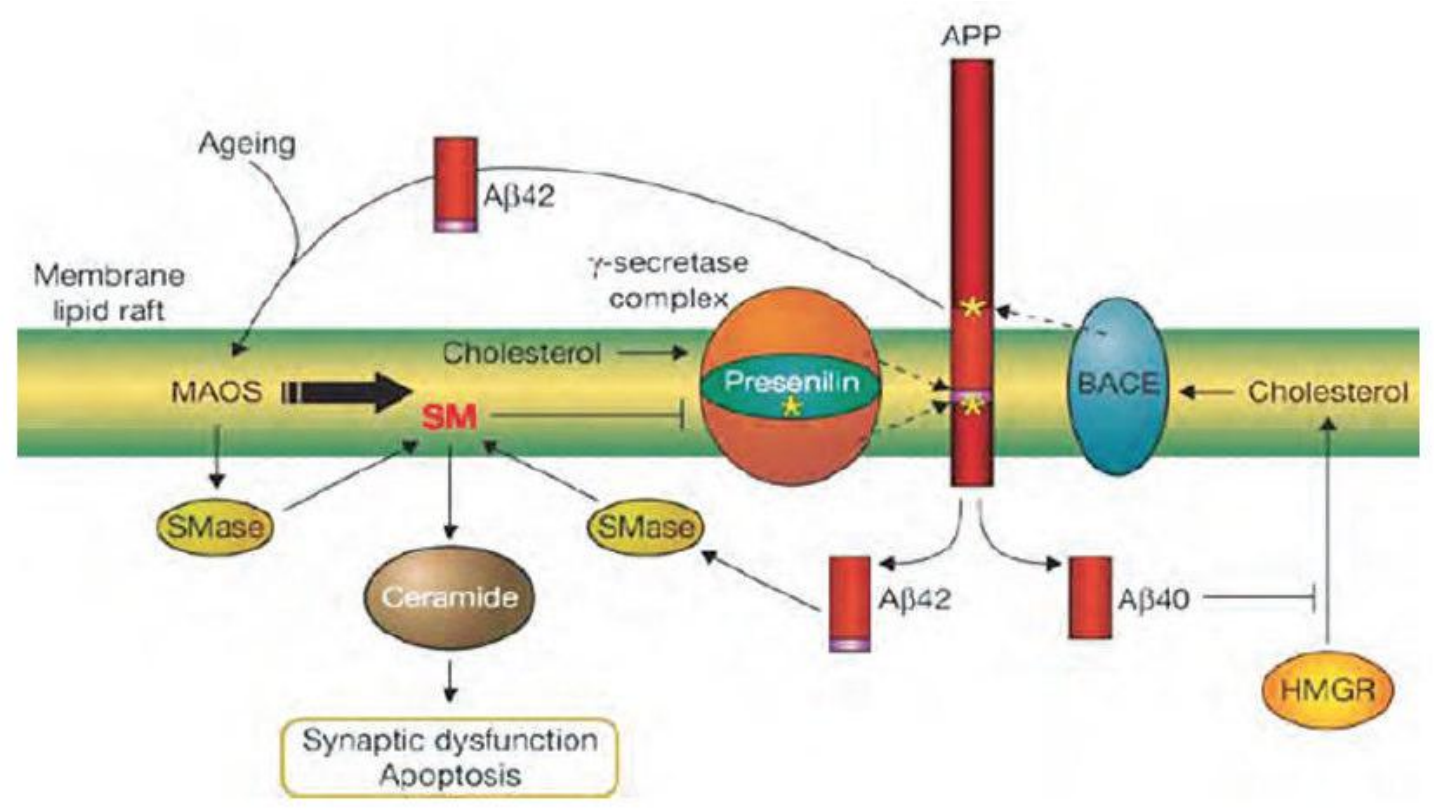

Figure 2. Interactions between membrane - lipid metabolism, APP processing and $A \beta$ neurotoxicity in $A D$ (Adapted with permission from Nature Publishing Groups).

metabolism, together with altered ceramide production, may cause dysfunction of synapses and render neurons vulnerable to apoptosis and excitotoxicity $(34,161)$.

An increase in the size of the amyloid $\beta$-peptide (A $\beta 42$ versus $A(440)$ may be a key factor in the pathogenesis of Alzheimer's disease. By altering the activities of enzymes involved in the metabolism of cholesterol and sphingomyelin, an increase in the $\mathrm{A} \beta 42: \mathrm{A} \beta 40$ ratio may cause dysfunction and death of neurons (161).

\section{AD Biomarkers}

The 'amyloid cascade theory' is the prevailing hypothesis on the cause of Alzheimer disease. It holds that an imbalance between production and clearance of $A \beta$ in the brain is the initiating event in the disease, ultimately leading to neuronal degeneration and dementia (36).

Substantial efforts have been made to translate the understanding of pathogenic mechanisms into therapeutic strategies. A major focus has been to inhibit production and aggregation of $A \beta$ and to increase its clearance from the brain-for example, by inhibiting $A \beta$-generating enzymes and by using $A \beta$ immunotherapy (33). A number of promising drug candidates are now under development. Such drugs with disease-modifying potential are likely to have the best efficacy in the early phase of the disease, when the neuronal degeneration has not become too widespread. This has initiated an intense search for Alzheimer disease biomarkers.

The first clinical phase in Alzheimer disease, typically characterized by isolated memory disturbances, is called mild cognitive impairment (MCI) (162). Only around $40-60 \%$ of individuals with MCI have incipient Alzheimer disease that will progress to Alzheimer disease with fullblown dementia, whereas others will develop different forms of dementia or have a benign form of MCI. As there is no clinical method to determine which $\mathrm{MCI}$ cases have incipient Alzheimer disease, there is a great need for biomarkers to identify these cases.

Another potential use for biomarkers is in clinical trials. At present, trials for new Alzheimer disease therapies often involve people with MCI. But these studies are impeded by the insufficiency of current criteria to identify MCI cases with incipient true Alzheimer disease (163).

The accuracy of the clinical diagnosis at the primary care level and in general hospitals is probably even lower, especially in the early stages of the disease when the symptoms are indistinct. In view of this, the need for specific $\mathrm{AD}$ markers is great. According to a proposal of a consensus group on molecular and biochemical markers of $\mathrm{AD}$ (164), an ideal marker of AD should be able to detect a fundamental feature of neuropathology and should be validated against neuropathologically confirmed cases. 
Furthermore, its sensitivity for detection of $\mathrm{AD}$ as well as its specificity for discrimination of $\mathrm{AD}$ from other dementia disorders should exceed $80 \%$. A marker for $\mathrm{AD}$ should also be reliable, reproducible, noninvasive, simple to perform in clinical routine and inexpensive (165).

\section{$\beta$-amyloid 42 (A $\beta 42)$, Total Tau (T-tau) and Phosphorylated Tau (P-tau)}

Underlying neuropathological changes in $\mathrm{AD}$ are the accumulation of senile plaques (SPs) and neurofibrillary tangles (NFTs). SPs are made up mainly of $\beta$-amyloid, especially the 42 -amino-acid is oform, $\beta$-amyloid 42 (A $\beta 42$ ) (166). The major constituent of NFTs is a cytoskeletonassociated protein called tau, which is hyperphosphorylated in NFTs (167). The golden standard of diagnosis is the identification of typical neuropathological changes in the brain of a patient who has suffered from clinical $\mathrm{AD}$.

Among several, we have focused on three candidates that have been suggested to fulfill the requirements for biomarkers of $\mathrm{AD}$ : $\beta$-amyloid42 (A $\beta 42)$, total tau (T-tau) and tau phosphorylated at various epitopes (P-tau). The cerebrospinal fluid (CSF) levels of these proteins reflect the metabolism of these proteins in the central nervous system (165).

\section{A $\beta 42$}

The central protein in SPs is A $\beta 42$. It is produced and secreted from human cells as a result of normal cellular processing of the larger transmembrane protein APP (168). In this processing, APP is cleaved in several steps and A $\beta$ is produced. In, AD, APP is first cleaved by an enzyme called $\beta$-secretase, which results in the release of a large $\mathrm{N}$-terminal fragment called $\beta$-secretase-cleaved soluble APP. In a second step, APP is cleaved by the $\gamma$-secretase complex, which results in the release of free $A \beta$. In this processing, various isoforms of $A \beta$, for example, $A \beta 42$, are produced; all of which are secreted into the CSF.

Using four different ELISA methods that are specific to A $\beta 42$ (169-172), more than 30 studies have consistently demonstrated a moderate to marked decrease in CSF $\mathrm{A} \beta 42$ in $\mathrm{AD}$. The principle for the ELISA that is most commonly used to measure A $\beta 42$ in CSF, INNOTEST ${ }^{\mathrm{TM}}$ $\beta$-AMYLOID $(1-42)(172$. There are 13 studies, including a total of about $600 \mathrm{AD}$ cases and 450 controls, in which sensitivity and specificity figures have been given or can be calculated from graphs. These studies show that, for CSF
$\mathrm{A} \beta 42$, the mean sensitivity for discrimination between $\mathrm{AD}$ and normal aging is approximately $86 \%$, while the specificity is approximately $91 \%$ and the mean level of decrease in $\mathrm{AD}$ patients compared with controls is about $50 \%$

On the other hand, the specificity for discrimination of $\mathrm{AD}$ from other disorders is moderate. Low levels of A $\beta 42$ in CSF have, for example, been found in Lewy body dementia $(173,174)$, a disorder also characterized by the presence of SPs. Low levels have also been found in a small percentage of patients with frontotemporal dementia and vascular dementia $(175,176)$ and also in CreutzfeldtJakob's disease $(177,178)$ and amyotrophic lateral sclerosis (179). These studies question the putative relation between low CSFA $\beta 42$ levels and the accumulation of SPs. There are several possible causes of low CSF-A $\beta 42$ levels, for example, axonal degeneration $(179,180)$ and entrapment in narrow interstitial and subarachnoid drainage pathways (179).

\section{T-tau}

Tau is a microtubule-associated protein which is located mainly in neuronal axons. By binding to microtubules, it promotes the stability and function of these. In the normal human brain, six different isoforms of tau are found, all of which have numerous phosphorylation sites (182). As tau is a major constituent of NFTs, CSF T-tau has been suggested as a marker for $\mathrm{AD}$. Using monoclonal antibodies that detect all isoforms of tau independent of degree of phosphorylation, enzyme-linked immunosorbent assays (ELISAs) have been developed that measure the T-tau levels in CSF (183-185). Using these ELISAs, more than 50 studies have consistently demonstrated a moderate to marked increase in CSF T-tau as well as high sensitivity and specificity of CSF-tau in $\mathrm{AD}$ patients when compared with controls. So far, CSF from about $2400 \mathrm{AD}$ patients and 1250 controls has been investigated in this way. The mean degree of increase is about $300 \%$ in $\mathrm{AD}$ compared with controls. The high sensitivity and specificity make CSF T-tau a good candidate for the designation biochemical marker for $\mathrm{AD}$, or $\mathrm{AD}$ biomarker. However, high levels of T-tau in the CSF have also been found in a proportion of cases with other dementia disorders, such as frontotemporal dementia $(186,187)$ and Lewy body dementia (173), but in several other disorders, for example, alcohol dementia, Parkinson's disease and depression, the CSF levels of T-tau seem to be normal and only occasionally increased (184,187-189).

It has been suggested that the CSF T-tau levels reflect the degree of neuronal (especially axonal) degeneration 
and damage (184). Some evidence for this has been found, for instance, a transient increase in CSF T-tau after acute stroke, with a positive correlation between CSF T-tau and infarct size as measured by computerized tomography [21], a very marked increase in CSF T-tau in Creutzfeldt-Jakob's disease (191), and a correlation between premortem CSF T-tau levels and the postmortem density of neurofibrillary tangles in the brain (192). Indirect evidence is that, in $\mathrm{AD}$ and controls, there is a positive correlation between the CSF levels of T-tau, GAP-43 and amyloid precursor protein (APP), all proteins located in the axon of neurons (193).

\section{P-Tau}

Tau is normally in a phosphorylated state. Over 70 phosphorylation sites are found on the human tau molecule and, in $\mathrm{AD}$, tau is usually in a hyperphosphorylated state. In $\mathrm{AD}$, this hyperphosphorylation involving certain epitopes on the tau molecule has the consequence that tau loses its ability to promote microtubule assembly and stability, which in turn leads to cytoskeleton instability and diminished transport ability $(194,195)$. A consequence of this is aggregation of tau with subsequent formation of NFTs (182). Several ELISAs have been developed that use monoclonal antibodies directed toward sites that are phosphorylated in AD. The principle for one of these ELISAs, INNOTEST ${ }^{\mathrm{TM}}$ PHOSPHO-TAU ${ }_{(181 P)}$, which measures tau phosphorylated at threonine $181\left(\mathrm{P}-\mathrm{Tau}_{181}\right)$ (197). Other ELISAs identify tau phosphorylated at the epitopes threonine 181 and $231\left(\mathrm{P}-\operatorname{tau}_{181}+231\right)(184)$, threonine 231 and serine $235\left(\mathrm{P}-\operatorname{tau}_{231}+235\right)$, serine 199 $\left(\mathrm{P}-\operatorname{tau}_{199}\right)(184)$, threonine $231\left(\mathrm{P}-\mathrm{tau}_{231}\right)(199)$ and serine 396 and $404\left(\mathrm{P}-\tan _{396+404}\right)(200)$. All these assays have shown increased CSF levels of P-tau in AD patients compared with controls. The sensitivity of CSF P-tau for discrimination between $\mathrm{AD}$ and normal aging is about the same or slightly lower as that of CSF T-tau, that is, about $75 \%$. Interestingly, the specificity of CSF P-tau for discrimination of $\mathrm{AD}$ from other dementias seems to be higher than those of CSF T-tau and CSF A 442 . Normal CSF levels of P-tau have been found in vascular dementia, frontotemporal dementia (201) and Lewy body dementia (202), which suggests that the above ELISAs may help to discriminate between $\mathrm{AD}$ and these dementias. In addition, while there is a marked increase in CSF T-tau after acute stroke, the CSF P-tau does not change (203). This suggests that the origin of increased CSF P-tau levels is more closely related to $\mathrm{AD}$ pathology, for instance, the formation of NFTs.

\section{Combination of CSF Markers}

The rationale for using the CSF levels of T-tau, Ah42 and $\mathrm{P}$-tau in combination to detect $\mathrm{AD}$ is very clear. Because the concentrations of any one of these substances is believed to reflect central pathogenetic processes in the disorder, that is, according to the leading hypothesis on the development of $\mathrm{AD}$, the amyloid cascade hypothesis, the combination might result in increased sensitivity and specificity. In fact, some large studies have shown that both sensitivity and specificity increase when, for instance, CSF T-tau and CSF A 342 are used in combination instead of being used alone $(173,175,204,205)$. Moreover, in a communitybased setting, the sensitivity for $\mathrm{AD}$ was more than $90 \%$, when combinations of the above $\mathrm{CSF}$ markers for $\mathrm{AD}$ were used in routine clinical chemistry analyses. The sensitivity and specificity figures were based on the values for all consecutive patients admitted for investigation of cognitive disturbances during 1 year (173).

High CSF levels of T-tau and low CSF levels of Ah42 in the early stages of $\mathrm{AD}$ have been found in several studies $(175,204,206-209)$. For more severely demented AD cases, the sensitivity figures are $80-90 \%$, suggesting that the two CSF markers are workable in the early stages of the disease process. Several studies have also found high CSF levels of T-tau and low CSF levels of A $\beta 42$ in patients with mild cognitive impairment (MCI) who later developed $\mathrm{AD}$ $(206,210,211)$. Increased CSF levels of T-tau were also found to discriminate, with high sensitivity and specificity, MCI patients whose disturbances later progressed to $\mathrm{AD}$ from the others (210). Other studies have also found increased CSF levels of P-tau in a high proportion of MCI cases $(210,211)$. These findings suggest that all three CSF markers may be of use in the clinical identification of $\mathrm{AD}$ in the very early phases of the disease and thus facilitate early intervention (165).

To simultaneously study several biomarkers for Alzheimer disease (AD), the xMAPTM technology has been develop and evaluate a multiparametric bead-based assay for quantification of $\beta$-amyloid $(1-42)\left[A \beta_{(1-42)}\right]$, total tau (T-TAU), and hyperphosphorylated tau $\left[\mathrm{P}-\mathrm{TAU}_{(181 \mathrm{P})}\right]$ in cerebrospinal fluid (CSF). The new multiparametric method may be able to replace the corresponding ELISA methods (212). 


\section{Visinin-like Protein 1 (VLP-1)}

Another class of biomarkers that may have utility in the diagnosis of $\mathrm{AD}$ are those that reflect neuronal death rather than specific markers of disease pathogenesis. Such markers may provide information about disease progression related to functional outcome and may have utility in future clinical trials testing therapeutic efficacy. Several reports have demonstrated the lack of correlation between amyloid plaque load and degree of dementia, suggesting that the former may not directly relate to the latter $(85,213)$. Therefore, a neuronal death biomarker might have greater correlation with dementia severity than the well-studied pathological biomarkers (214).

Quantified the levels of a brain injury marker, visininlike protein 1 (VLP-1, also abbreviated as VILIP-1 or VSNL-1), in CSF of AD patients and age-matched controls. VLP-1 belongs to the family of neuronal calcium sensor proteins involved in calcium-dependent signal transduction mechanisms in neurons. VLP-1 increases neuronal cyclic adenosine monophosphate levels by inducing protein kinase A. VLP-1 is expressed in neurons (215) and its immunoreactivity is decreased in brains of $\mathrm{AD}$ patients compared to controls (216). Remarkably, VLP-1 expression is associated with neurofibrillary tangles in $\mathrm{AD}$ brains (217). The investigation of the concentration of VLP-1 in CSF reported by Lee et al. was based on findings they reported (218). VLP-1 appeared to be a protein that was relatively brain specific; its concentration was increased in plasma of stroke patients and in CSF in a rat model for stroke, suggesting that VLP-1 is a marker for (rapid) neuronal cell injury. In the present study, CSF VLP-1 concentrations were $50 \%$ higher in $\mathrm{AD}$ patients than in the control population. An interesting aspect of the studies of Lee and colleagues is that their original approach to find novel markers of brain injury, i.e., mRNA profiling and selection for products that were highly enriched in brain tissue (218), resulted in the identification of VLP-1, which was not picked up by comparable fishing expeditions using a proteomics approach with human CSF from $\mathrm{AD}$ patients (219).

Interestingly, VLP-1 concentrations in AD patients with an apolipoprotein $\mathrm{E}(A P O E) \varepsilon 4 / \varepsilon 4$ genotype were approximately double those in $\varepsilon 3 / \varepsilon 3$ carriers. Although the current study includes a relatively small patient series and the results await confirmation in larger cohorts and fro $\mathrm{m}$ independent studies, this association of VLP-1 with the $A P O E$ genotype seems to be remarkably different from the association of the $A P O E$ genotype with T-tau concentrations (214).

Another remarkable finding by Lee et al. is the correlation between Mini Mental Status Examination (MMSE) scores as a marker for disease severity and CSF VLP-1 concentrations. Many reported studies have found no correlation of CSF A $\beta 42$ and T-tau with MMSE score [summarized in (220) and confirmed in the small cohort described by Lee et al. (214). VLP-1 is negatively correlated to MMSE scores, suggesting VLP-1 may also have a role as a biomarker of disease severity, and role in monitoring disease activity (loss of neurons and cognition per period of time) can also be envisioned. The findings of MMSE correlation with VLP-1, however, should be confirmed in wider ranges of MMSE values and larger groups.

Finally, as Lee et al. point out in their report, the real clinical challenge is not the differentiation of patients with $\mathrm{AD}$ from controls but of patients with $\mathrm{AD}$ from patients with other types of dementia, including vascular dementia, dementia with Lewy bodies, or frontotemporal lobe degeneration, and also in patients whose dementia is attributable to treatable disorders such as vitamin deficiencies, depression, alcohol abuse, and normalpressure hydrocephalus (221).

\section{Miscellaneous Brain-Spesific Proteins}

A variety of other brain-injury biomarkers have been examined in the CSF of patients with dementia, including neuron-specific enolase $(223,224), S 100 \beta$ protein (225), and glial fibrillary acidic protein (GFAP) (226), all with variable diagnostic specificity and sensitivity. More recently, proteomic profiling has resulted in the identification of several candidate biomarkers (227), including heart-fatty acid binding protein $(228,229)$, Park 7 , and nucleoside diphosphate kinase A (230). The effectiveness of a fluid biomarker is dependent on a multitude of factors, including organ specificity, accumulation in accessible body fluids, stability, clearance, and detectability. Direct comparisons between biomarker candidates will be important to identify such an ideal biomarker.

$A P O E$ genotype is the strongest known genetic risk factor for the development of late-onset $\mathrm{AD}$, with the $\varepsilon 4$ allele incurring greatest risk $(25,142,231)$. The molecular mechanism for this risk is not known; however, it is believed that $\mathrm{ApoE}$ protein may play a role in $\mathrm{A} \beta$ transport/ clearance (232), and that the genotype may also impart increased vulnerability to a variety of central nervous system injuries (233). 
With the increasing clinician awareness that CSF biomarkers have additional value in the diagnostic workup of dementia patients and that CSF analysis appears likely to gain a position in the diagnostic (research) criteria for $\mathrm{AD}$, this study will motivate other researchers in their quest to find specific biomarkers for dementia syndromes (221).

\section{Plasma Signaling Proteins}

Because the brain controls many body functions via the release of signaling proteins, and because central and peripheral immune and inflammatory mechanisms are increasingly implicated in Alzheimer's (7) and related diseases4, Ray et al hypothesized that the pathological processes leading to Alzheimer's would cause characteristic changes in the concentrations of signaling proteins in the blood, generating a detectable disease-specific molecular phenotype (235).

The computational gene network prediction tool Ingenuity Pathway Analysis (Ingenuity Systems) identified two independent regulatory networks connecting the 18 signaling proteins. One network centered on tumor necrosis factor (TNF)-a and monocyte-colony stimulating factor (M-CSF), whereas the other centered on epidermal growth factor (EGF). Consistent with these findings, gene ontology (Kyoto Encyclopedia of Genes and Genomes; http://www.genome.jp/kegg/) and BioCarta (http://www. biocarta. com/) pathway analyses indicated involvement of the 18 markers in immune response, hematopoiesis and apoptosis (235).

A decrease in the abundance of factors linked to hematopoiesis would be particularly noteworthy in light of recent data suggesting that hematopoietic cells can enter the brain in Alzheimer's disease or in Alzheimer's mouse models at increased frequencies and modulate the disease $(7,236,237)$. Dysfunction of apoptotic pathways has also been linked to Alzheimer's disease (238).

The observed dysregulation of the signaling pathways represented by the 18 signaling proteins in blood plasma may point to changes in the periphery, the central nervous system or both that are relatively specific to Alzheimer's disease and occur early in the disease process.

Studied by Ray et al found 18 signaling proteins in blood plasma that can be used to classify blinded samples from Alzheimer's and control subjects with close to $90 \%$ accuracy and to identify patients who had mild cognitive impairment that progressed to Alzheimer's disease
2-6 years later. Biological analysis of the 18 proteins points to systemic dysregulation of hematopoiesis, immune responses, apoptosis and neuronal support in presymptomatic Alzheimer's disease (235).

\section{Conclusions}

For the time being, a presumptive diagnosis of Alzheimer's can be made clinically using various cognition tests, neurological exams, and patient history. A definitive diagnosis is possible only through post - mortem brain analysis. Unfortunately, by the time symptoms appear and a clinical diagnosis is made, the disease has been simmering for decades and intractable neurological damage occurred (239).

Development of disease-specific CSF, serum and urine biomarkers will undoubtedly add to the process of differential diagnosis early in the course of the disease (220).

\section{References:}

1. Cummings JL. Alzheimer's disease. N Engl J Med 2004; 351 : $56-67$.

2. Vas CJ. Alzheimer's disease: the brain killer. World Health Organization 2001

3. Mount C, Downtown C. Alzheimer disease: progress or profit? Nat Med 2006; 12: 780 - 784 .

4. Mandavilli A. The amyloid code. Nat Med 2006; 12: 747 749 .

5. Kins S, Beyreuther. Teasing out the tangles. Nat Med 2006, 12 : 764 .

6. Rozemuller J M, Eikelenboom P, Stam FC. Role of microglia in plaque formation in senile dementia of the Alzheimer type. An immunohistochemical study. Virchows Arch B Cell Pathol 1986; 51: 247-254.

7. Wyss-Coray T. Inflammation in Alzheimer disease: driving force, bystander or beneficial response? Nat Med 2006; 12: 1005-1015.

8. Markesbery WR. Oxidative stress hypothesis in Alzheimer's disease. Free Radic Biol Med 1997; 23: 134-147.

9. McGeer PL, Rogers J, McGeer EG. Inflammation, antiinflammatory agents and Alzheimer disease: the last 12 years. J Alzheimers Dis 2006; 9: 271-276.

10. McKhann G, Drachman D, Folstein M, Katzman R, Price D, Stadlan EM. Clinical diagnosis of Alzheimer's disease: report of the NINCDS-ADRDA Work Group under the auspices of Department of Health and Human Services Task Force on Alzheimer's Disease. Neurology 1984; 34 : 939-944.

11. Hui $H$, Lee A-E. Clinical criteria for dementia subtypes. In: Qizilbash N, Schneider L, Brodaty H, et al., eds. Evidencebased dementia practice. Oxford, England: Blackwell Science, 2002:106-119. 
12. Gearing M, Mirra SS, Hedreen JC, Sumi SM, Hansen LA, Heyman A. The Consortium to Establish a Registry for Alzheimer's Disease (CERAD). Part X. Neuropathology confirmation of the clinical diagnosis of Alzheimer's disease. Neurology 1995; 45: 461-466.

13. Chong MS, Sahadevan S. Preclinical Alzheimer's disease: diagnosis and prediction of progression. Lancet Neurol 2005; 4: 576-579.

14. Hansson $\mathrm{O}$, Zetterberg $\mathrm{H}$, Buchhave $\mathrm{P}$, Londos $\mathrm{E}$, Blennow $\mathrm{K}$, Minthon L. Association between CSF biomarkers and incipient Alzheimer's disease in patients with mild cognitive impairment: a follow-up study. Lancet Neurol 2006; 5: 228-234.

15. Ferri $\mathrm{CP}$, Prince $\mathrm{CM}$, Brayne $\mathrm{C}$, et al. Global prevalence of dementia: a Delphi consensus study. Lancet 2005; 366 : $2112-2117$.

16. Mayeux R. Epidemiology of neurodegeneration. Annu Rev Neurosci 2003; 26: 81-104.

17. Mortimer JA, Snowdon DA, Markesbery WR. Head circumference, education and risk of dementia: fi ndings from the Nun Study. J Clin Exp Neuropsychol 2003; 25 : 671-79.

18. Jellinger KA. Head injury and dementia. Curr Opin Neurol 2004; 17: 719-23.

19. Luchsinger JA, Mayeux R. Dietary factors and Alzheimer's disease. Lancet Neurol 2004; 3: 579-87.

20. Gatz M, Reynolds CA, Fratiglioni L, et al. Role of genes and environments for explaining Alzheimer disease. Arch Gen Psychiatry 2006; 63: 168-74.

21. Goate A, Chartier-Harlin MC, Mullan M, et al. Segregation of a missense mutation in the amyloid precursor protein gene with familial Alzheimer's disease. Nature 1991; 349: 70406 .

22. Sherrington R, Rogaev El, Liang $\mathrm{Y}$, et al. Cloning of a gene bearing missense mutations in early-onset familial Alzheimer's disease. Nature 1995; 375: 754-60.

23. Levy-Lahad E, Wasco W, Poorkaj $P$, et al. Candidate gene for the chromosome 1 familial Alzheimer's disease locus. Science 1995; 269: 973-77.

24. Harvey RJ, Skelton-Robinson M, Rossor MN. The prevalence and causes of dementia in people under the age of 65 years. J Neurol Neurosurg Psychiatry 2003; 74: 120609 .

25. Corder EH, Saunders AM, Strittmatter WJ, et al. Gene dose of apolipoprotein E type 4 allele and the risk of Alzheimer's disease in late onset families. Science 1993; 261: 92123.

26. Poirier J, Davignon J, Bouthillier D, Kogan S, Bertrand P, Gauthier S. Apolipoprotein E polymorphism and Alzheimer's disease. Lancet 1993; 342: 697-99.

27. Farrer LA, Cupples LA, Haines JL, et al. Eff ects of age, sex, and ethnicity on the association between apolipoprotein $\mathrm{E}$ genotype and Alzheimer disease: a meta-analysis. JAMA 1997; 278: 1349-56.

28. Meyer MR, Tschanz JT, Norton MC, et al. ApoE genotype predicts when-not whether-one is predisposed to develop Alzheimer's disease. Nature Genetics 1998; 19: 321-22.

29. Poirier J. Apolipoprotein $\mathrm{E}$ in animal models of CNS injury and in Alzheimer's disease. Trends Neurosci 1994; 17: 52530 .

30. Holtzman DM, Bales KR, Tenkova T, et al. Apolipoprotein $\mathrm{E}$ isoform-dependent amyloid deposition and neuritic degeneration in a mouse model of Alzheimer's disease. Proc Natl Acad Sci USA 2000; 97: 2892-97.

31. Prince JA, Zetterberg $\mathrm{H}$, Andreasen $\mathrm{N}$, Marcusson J, Blennow K. APOE epsilon4 allele is associated with reduced cerebrospinal fl uid levels of Abeta42. Neurology 2004; 62: 2116-18

32. Raber J, Huang Y, Ashford JW. ApoE genotype accounts for the vast majority of $A D$ risk and $A D$ pathology. Neurobiol Aging 2004; 25 : 641-50.

33. Blennow K, de Lean MJ, Zetterberg H. Alzheimer's disease. Lancet 2006; 368: $387-403$.

34. Mattson MP. Pathways towards and away from alzheimer's disease. Nature 2004; 430: 631 - 639

35. Selkoe DJ. Deciphering the genesis and fate of amyloid $\beta$-protein yields novel therapies for Alzheimer disease. $J$ Clin Invest 2002; 110: 1375 - 1381.

36. Hardy J, Selkoe D J. The amyloid hypothesis of Alzheimer's disease: progress and problems on the road to therapeutics. Science 2002; 297: 353-356.

37. Selkoe D, Kopan R. Notch and presenilin: regulated intramembrane proteolysis links development and degeneration. Annu Rev Neurosci 2003; 26: 565-597.

38. Shen J, Kelleher RJ. The presenilin hypothesis of Alzheimer's disease: evidence for a loss-of-function pathogenic mechanism. Proc Natl Acad Sci USA 2007; 104: 403409.

39. Hardy J, Cullen K. Amyloid at the blood vessel wall. Nat Med 2006; $12: 756-757$.

40. Xu F, Davis J, Miao J, et al. Protease nexin-2/amyloid betaprotein precursor limits cerebral thrombosis. Proc Nat Acad Sci USA 2005; 102: 18135-18140.

41. Weller RO, Massey A, Newman TA, Hutchings M, Kuo YM, Roher AE. Cerebral amyloid angiopathy: amyloid beta accumulates in putative interstitial fluid drainage pathways in Alzheimer's disease. Am J Pathol 1999; 153: 725733.

42. Lambert MP, Barlow AK, Chromy BA, et al. Diffusible, nonfibrillar ligands derived from Abeta1-42 are potent central nervous system neurotoxins. Proc Natl Acad Sci USA 1998; 95: 6448-6453.

43. Dotti CG, De Strooper B. Alzheimer's dementia by circulation disorders: when trees hide the forest. Nat Cell Biol 2009; 11: $114-116$.

44. Bell RD, Deane R, Chow N, et al. SRF and myocardin regulate LRP-mediated amyloid-beta clearance in brain vascular cells. Nat Cell Biol 2009; 11: 143 - 153.

45. Shibata M, Yamada S, Kumar SR, et al. Clearance of Alzheimer's amyloid-ss(1-40) peptide from brain by LDL receptor-related protein-1 at the blood-brain barrier. J Clin Invest 2000; 106: 1489 - 1499.

46. Niwa K, Younkin L, Ebeling C, et al. Abeta 1-40-related reduction in functional hyperemia in mouse neocortex during somatosensory activation. Proc Natl Acad Sci USA 2000; 97: 9735 - 9740 .

47. de la Torre JC. Critically attained threshold of cerebral hypoperfusion: the CATCH hypothesis of Alzheimer's pathogenesis. Neurobiol Aging 2000; 21: 331 - 342.

48. Ladecola C. Neurovascular regulation in the normal brain and in Alzheimer's disease. Nat Rev Neurosci 2004; 5: 347 360.

49. Zlokovic BV. The blood-brain barrier in health and chronic neurodegenerative disorders. Neuron 2008; 57: 178 201.

50. Smith EE. Greenberg SM. $\beta$-Amyloid, blood vessels, and brain function. Stroke 2009; 40: 2601 - 2606.

51. Mattson MP. Cellular actions of beta-amyloid precursor protein and its soluble and fibrillogenic derivatives. Physiol Rev 1997; 77: 1081-1132.

52. Kimberly WT, Zheng JB, Guénette SY, Selkoe DJ. The intracellular domain of the beta-amyloid precursor protein 
is stabilized by Fe65 and translocates to the nucleus in a notch-like manner. J Biol Chem 2001; 276: 4028840292.

53. Scheuner D, Eckman C, Jensen M, et al. Secreted amyloid beta-protein similar to that in senile plaques of Alzheimer's disease is increased in vivo by the presenilin 1 and 2 APP mutations linked to familial Alzheimer's disease. Nature Med 1996; 2: 864-870.

54. Chapman PF, White GL, Jones MW, et al. Impaired synaptic plasticity and learning in aged amyloid precursor protein transgenic mice. Nature Neurosci 1999; 2: 271-276.

55. Chan SL, Furukawa K, Mattson MP. Presenilins APP in neuritic and synaptic plasticity: implications fot the pathogenesis of Alzheimer's disease. Neuromolecular Med 2002; 2: 167 $-196$.

56. Ihara $Y$, Nukina N, Miura R, Ogawara M. Phosphorylated tau protein is integrated into pairedhelical filaments in Alzheimer's disease. J Biochem 1986; 99: 1807-1810.

57. Kosik KS, Joachim CL, Selkoe D J. Microtubule-associated protein tau (T) is a major antigenic component of paired helical filaments in Alzheimer disease. Proc Natl Acad Sci USA 1986; 83: 4044-4048.

58. Edbauer D, Winkler E, Regula JT, Pesold B, Steiner H, Haass C. Reconstitution of gamma-secretase activity. Nat Cell Biol 2003; 5: 486 - 488 .

59. Yu G, Nishimura M, Arawaka S, et al. Nicastrin modulates presenilin-mediated notch/glp-1 signal transduction and betaAPP processing. Nature 2000; 407: 48 - 54.

60. Chung HM, Struhl G. Nicastrin is required for Presenilinmediated transmembrane cleavage in Drosophila. Nat Cell Biol 2001; 3: 1129 - 1132

61. De Strooper B, Annaert W, Cupers P, et al. A presenilin-1dependent gamma-secretase-like protease mediates release of Notch intracellular domain. Nature 1999; 398 : $518-522$

62. Francis R, McGrath G, Zhang J, et al. aph-1 and pen-2 are required for Notch pathway signaling, gamma-secretase cleavage of betaAPP, and presenilin protein accumulation. Dev Cell 2002; 3: 85 - 97.

63. Goutte C, Tsunozaki M, Hale VA, Priess JR. APH-1 is a multipass membrane protein essential for the Notch signaling pathway in Caenorhabditis elegans embryos. Proc Natl Sci USA 2002; 99: 775 - 779.

64. Takasugi N, Tomita T, Hayashi I. The role of presenilin cofactors in the gamma-secretase complex. Nature 2003; $422: 438$ -441 .

65. Takashima A, Shimojo M, Wolozin B. The players on the Y-secretase team. Nat Med 2006; 12: 766 - 767.

66. Faghihi MA, Modarresi F, Khalil AM. Expression of a noncoding RNA is elevated in Alzheimer's disease and drives rapid feed-forward regulation of beta-secretase. Nat Med 2008; 14: $723-730$

67. St George - Hyslop P, Haass C. Regulatory RNA goes awry in alzheimer's disease. Nat Med 2008; 14: 711 - 712

68. Buee L, Bussiere T, Buee-Scherrer V, Delacourte A, Hof PR. Tau protein isoforms, phosphorylation and role in neurodegenerative disorders. Brain Res Rev 2000; 33: 95-130.

69. Ballatore C, Lee VMY, Trojanowski JQ. Tau - mediated neurodegeneration in alzheimer's disease and related disorders. Nat Rev Neurosci 2007; 8: 663 - 672.

70. Lee G, Neve RL, Kosik KS. The microtubule binding domain of tau protein. Neuron 1989; 2: 1615-1624.

71. Kampers $T$, Pangalos $M$, Geerts $H$, Wiech $H$, Mandelkow $E$. Assembly of paired helical filaments from mouse tau: implications for the neurofibrillary pathology in transgenic mouse models for Alzheimer's disease. FEBS Lett 1999;
451: $39-44$.

72. Takashima A, Murayama M, Murayama $\mathrm{O}$, et al. Presenilin 1 associates with glycogen synthase kinase- $3 \beta$ and its substrate tau. Proc Natl Acad Sci USA 1998; 95: 96379641.

73. Lee G. Tau and src family tyrosine kinases. Biochim Biophys Acta 2005; 1739: 323-330

74. Brandt R, Leger J, Lee G. Interaction of tau with the neural plasma membrane mediated by tau's amino-terminal projection domain. J Cell Biol 1995; 131: 1327-1340.

75. Maas T, Eidenmuller J, Brandt R. Interaction of tau with the neural membrane cortex is egulated by phosphorylation at sites that are modified in paired helical filaments. J Biol Chem 2000; 275: 15733-15740.

76. Kuret J, Congdon EE, Li G, Yin H, Yu X, Zhong Q. Evaluating triggers and enhancers of tau fibrillization. Microsc Res Tech 2005; 67: 141-155.

77. MazanetzMP, FischerPM. Untangling tau hyperphosphorylation in drug design for neurodegenerative diseases. Nature Rev Drug Discov 2007; 6: 464-479.

78. Andersen JK. Oxidative stress in neurodegeneration: cause or consequence? Nature Med 2004; 5: S18-S25

79. Moreira PI, Siedlak SL, Aliev G, et al. Oxidative stress and neurodegeneration. Ann NY Acad Sci 2005; 1043: 545552.

80. King ME, Kan HM, Baas PW, Erisir A, Glabe CG, Bloom GS. Tau-dependent microtubule disassembly initiated by prefibrillar $\beta$-amyloid. J Cell Biol 2006; 175: 541-546.

81. Rapoport M, Dawson HN, Binder LI, Vitek MP, Ferreira A. Tau is essential to $\beta$-amyloid-induced neurotoxicity. Proc Natl Acad Sci USA 2002; 99: 6364-6369.

82. Liu Q, Lee HG, Honda $\mathrm{K}$, et al. Tau modifiers as therapeutic targets for Alzheimer's disease. Biochim Biophys Acta 2005; 1739: 211-215.

83. Forman MS, Trojanowski JQ, Lee VM. Neurodegenerative diseases: a decade of discoveries paves the way for therapeutic breakthroughs. Nature Med 2004; 10: 10551063.

84. Trojanowski JQ, Mattson MP. Overview of protein aggregation in single, double, and tripleneurodegenerative brain amyloidoses. Neuromolecular Med 2003; 4: 1-6.

85. Arriagada PV, Growdon JH, Hedley-Whyte E T, Hyman BT. Neurofibrillary tangles but not senile plaques parallel duration and severity of Alzheimer's disease. Neurology 1992; 42: 631-639.

86. Arriagada PV, Marzloff K, Hyman BT. Distribution of Alzheimertype pathologic changes in nondemented elderly individuals matches the pattern in Alzheimer's disease. Neurology 1992; 42: 1681-1688.

87. Lin MT, Beal MF. Mitochondrial dysfunction and oxidative stress in neurodegenerative diseases. Nature 2006; 443 $787-795$.

88. Nunomura A, Perry G, Aliev G, et al. Oxidative damage is the earliest event in Alzheimer disease. J Neuropathol Exp Neurol 2001; 60: 759-767.

89. Pratico D, Uryu K, Leight S, Trojanoswki J Q, Lee VM. Increased lipid peroxidation precedes amyloid plaque formation in an animal model of Alzheimer amyloidosis. $J$ Neurosci 2001; 21: 4183-4187.

90. Reddy PH, McWeeney S, Park BS, et al. Gene expression profiles of transcripts in amyloid precursor protein transgenic mice: up-regulation of mitochondrial metabolism and apoptotic genes is an early cellular change in Alzheimer's disease. Hum Mol Genet 2004; 13 1225-1240.

91. Tamagno E, Parola M, Bardini $P$, et al. $\beta$-Site APP cleaving 
enzyme up-regulation induced by 4-hydroxynonenal is mediated by stress-activated protein kinases pathways. $J$ Neurochem 2005; 92: 628-636.

92. Lovell MA, Xiong S, Xie C, Davies P, Markesbery WR. Induction of hyperphosphorylated tau in primary rat cortical neuron cultures mediated by oxidative stress and glycogen synthase kinase-3. J Alzheimers Dis 2004; 6: 659-671.

93. Sultana R, Boyd-Kimball D, Poon HF, et al. Oxidative modification and down-regulation of Pin1 in Alzheimer's disease hippocampus: a redox proteomics analysis. Neurobiol Aging 2006; 27: 918-925.

94. Hansson CA, Frykman S, Farmery MR, et al. Nicastrin, presenilin, APH-1, and PEN-2 form active gammasecretase complexes in mitochondria. $J$ Biol Chem 2004; 279: $51654-51660$.

95. Leissring MA, Farris $\mathrm{W}, \mathrm{Wu} \mathrm{X}$, et al. Alternative translation initiation generates a novel isoform of insulin-degrading enzyme targeted to mitochondria. Biochem J 2004; 383 : $439-446$.

96. Falkevall A, Alikhani N, Bhushan S, et al. Degradation of the amyloid beta-protein by the novel mitochondrial peptidasome, PreP. J Biol Chem 2006; 281: 29096 29104.

97. Sanz-Blasco S, Valero RA, Rodriguez-Crespo I, Villalobos C, Nunez L. Mitochondrial $\mathrm{Ca} 2+$ overload underlies Abeta oligomers neurotoxicity providing an unexpected mechanism of neuroprotection by NSAIDs. Plos ONE 2008; 3: e2718.

98. Starkov AA, Beal FM. Portal to alzheimer's disease. Nat Med 2008; 14: 1020 - 1021.

99. Park L, Anrather J, Zhou P, et al. NADPH Osidase - derived Reactive Oxygen Species mediate the cerebrovascular dysfunction induced by the amyloid $\beta$ peptide. J Neurosci 2005; 25: $1769-1777$.

100. Akiyama $\mathrm{H}$, Barger $\mathrm{S}$, Barnum $\mathrm{S}$, et al. Inflammation and Alzheimer's disease. Neurobiol Aging 2000; 21: 383421.

101. Wyss-Coray T, YanF, LinAH, etal. Prominentneurodegeneration and increased plaque formation in complement-inhibited Alzheimer's mice. Proc Natl Acad Sci USA 2002; 99: 10837-10842.

102. Tesseur I, Zou K, Esposito L, et al. Deficiency in neuronal TGF- $\beta$ signaling promotes neurodegeneration and Alzheimer's pathology. J Clin Invest 2006; 116: 3060-3069.

103. Das $P$, Golde T. Dysfunction of TGF- $\beta$ signaling in alzheimer's disease. J Clin Invest 2006; 116: 2855 - 2857

104. Wyss-Coray $\mathrm{T}$, Mucke $\mathrm{L}$. Inflammation in neurodegenerative disease--a double-edged sword. Neuron 2002; 35: 419432.

105. Glabe CC. Amyloid accumulation and pathogensis of Alzheimer's disease: significance of monomeric, oligomeric and fibrillar Abeta. Subcell Biochem 2005; 38 : 167-177

106. Kayed R, Head E, Thompson JL, et al. Common structure of soluble amyloid oligomers implies common mechanism of pathogenesis. Science 2003; 300: 486-489.

107. Jarvik GP, Wijsman EM, Kukull WA, Schellenberg GD, Y C, Larson EB. Interactions of apolipoprotein E genotype, total cholesterol level, age, and sex in prediction of Alzheimer's disease: A case-control study. Neurology 1995; 45: 10921096.

108. Kuo YM, Emmerling MR, Bisgaier CL, et al. Elevated lowdensity lipoprotein in Alzheimer's disease correlates with brain A $1-42$ levels. Biochem Biophys Res Commun 1998; 252: 711-715.

109. Wolozin B, Kellman W, Ruosseau P, Celesia GG, Siegel G. Decreased prevalence of Alzheimer disease associated with 3- hydroxy-3-methylglutaryl coenzyme A reductase inhibitors. Arch Neurol 2007; 57: 1439-1443.

110. Jick H, Zornberg GL, Jick SS, Seshadri S, Drachman DA. Statins and the risk of dementia. Lancet 2000; 356: 1627 1631

111.Raffai RL, Weisgraber KH. Cholesterol: from heart attacks to alzheimer's disease. J Lipid Res 2003; 44: 1423 - 1430.

112. Bodovitz S, Klein WL. Cholesterol modulates $\beta$-secretase cleavage of amyloid precursor protein. J Biol Chem 1996; 271: $4436-4440$

113. Lee SJ, Liyanage U, Bickel PE, Xia W, Lansbury Jr. PT, Kosik KS. A detergent-insoluble membrane compartment contains A $\beta$ in vivo. Na. Med 1998; 4: 730-734.

114. Wahrle S, Das P, Nyborg AC, McLendon C, et al. Cholesteroldependent $\beta$-secretase activity in buoyant cholesterol-rich membrane microdomains. Neurobiol Di 2002; 9: 11-23.

115. Yanagisawa K, Matsuzaki K. Cholesterol-dependent aggregation of amyloid $\beta$-protein. Ann N Y Acad Sci 2002; 977: 384-386.

116. Zlokovic BV, Martel CL, Matsubara E, et al. Glycoprotein 330/ megalin: probable role in receptor-mediated transport of apolipoprotein $\mathrm{J}$ alone and in a complex with Alzheimer disease amyloid $\mathrm{b}$ at the blood-brain and bloodcerebrospinal fluid barriers. Proc Natl Acad Sci USA 1996; 93: $4229-4234$

117. Bell RD, Sagaare AP, Friedman AE, et al. Transport pathways for clearance of human Alzheimer's amyloid b-peptide and apolipoproteins $\mathrm{E}$ and $\mathrm{J}$ in the mouse central nervous system. J Cereb Blood Flow Metab 1 November 2006; e-pub ahead of print

118. Burns M, Gaynor K, Olm V, et al. Presenilin redistribution associated with aberrant cholesterol transport enhances b-amyloid production in vivo. $J$ Neurosci 2003 ; 23:56455649

119. Shie FS, Jin LW, Cook DG, et al. Diet-induced hypercholesterolemia enhances brain A beta accumulation in transgenic mice. Neuroreport 2002; 213:455-459.

120. RefoloLM,PappollaMA, MalesterB, etal. Hypercholesterolemia accelerates the Alzheimer's amyloid pathology in a transgenic mouse model. Neurobiol Dis 2000; 7:321331.

121. Fassbender $\mathrm{K}$, Simons M, Bergmann $\mathrm{C}$, et al. Simvastatin strongly reduces levels of Alzheimer's disease b-amyloid peptides $\mathrm{Ab} 42$ and $\mathrm{Ab} 40$ in vitro and in vivo. Proc Natl Acad Sci USA 2001; 98:5856-5861.

122. Kojro E, Gimple G, Lammich S, et al. Low cholesterol stimulates the nonamyloidogenic pathway by its effect on the a-secretase ADAM 10. Proc Natl Acad Sci USA 2001; 98:5815-5820.

123. Simons M, Keller P, De Strooper B, et al. Cholesterol depletion inhibits the generation of b-amyloid in hippocampal neurons. Proc Natl Acad Sci USA 1998; 95:6460-6464.

124. Buxbaum JD, Geoghagan NS, Friedhoff LT. Cholesterol depletion with physiological concentrations of a statin decreases the formation of the Alzheimer amyloid Abeta peptide. J Alzheimer's Dis 2001; 3:221-229.

125. Ehehalt $R$, Keller $P$, Haass $C$, et al. Amyloidogenic processing of the Alzheimer $\beta$-amyloid precursor protein depends on lipid rafts. J Cell Biol 2003; 160: 113-123.

126. Hirsch-Reinshagen V, Wellington CL. Cholesterol metabolism, apolipoprotein $E$, adenosine triphosphate - binding cassette transporters, and alzheimer's disease. Curr Opin Lipidol 2007; 18: 325 - 332.

127. Dietschy JM, Turley SD. Cholesterol metabolism in the brain. Curr Opin Lipidol 2001; 12: 105-112.

128. Björkhem I, Lütjohann D, Breuer $O$, Sakinis A, Wennmalm A. Importance of a novel oxidative mechanism for elimination 
of brain cholesterol: Turnover of cholesterol and 24Shydroxycholesterol in rat brain as measured with 1802 techniques in vivo and in vitro. $\mathrm{J} \mathrm{Biol} \mathrm{Chem} \mathrm{1997;} 272$ : 30178-30184.

129. Lütjohann D, Breuer O, Ahlborg G, et al. Cholesterol homeostasis in human brain: Evidence for an agedependent flux of 24S-hydroxycholesterol from the brain into the circulation. Proc Natl Acad Sc. USA 1996; 93: 9799-9804.

130. Lund EG, Guileyardo JM, Russell DW. cDNA cloning of cholesterol 24-hydroxylase, a mediator of cholesterol homeostasis in the brain. Proc Natl Acad Sci USA 1999; 96: 7238-7243.

131. Papassotiropoulos A, Lütjohann D, Bagli $M$, et al 24Shydroxycholesterol in cerebrospinal fluid is elevated in early stages of dementia. J Psychiatr Res 2002; 36: 2732.

132. Lütjohann D, Papassotiropoulos A, Björkhem I, et al. Plasma 24S-hydroxycholesterol (cerebrosterol) is increased in Alzheimer and vascular demented patients. $J$ Lipid Res 2000; 41: 195-198.

133. Schönknecht $P$, Lütjohann D, Pantel J, et al. Cerebrospinal fluid 24S-hydroxycholesterol is increased in patients with Alzheimer's disease compared to healthy controls. Neurosci Lett 2002; 324: 83-85.

134. Kölsch H, Ludwig M, Lütjohann D, Rao ML. Neurotoxicity of 24 hydroxycholesterol, an important cholesterol elimination product of the brain, may be prevented by vitamin $\mathrm{E}$ and estradiol-17ß. J Neural Transm 2001; 108: 475-488.

135. Bretillon L, Lütjohann D, Ståhle L, et al. Plasma levels of $24 \mathrm{~S}$ hydroxycholesterol reflect the balance between cerebral production and hepatic metabolism and are inversely related to body surface. J Lipid Res 2000; 41: 840-845.

136. Vega GL, Weiner MF, Lipton AM, et al. Reduction in levels of 24S-hydroxycholesterol by statin treatment in patients with Alzheimer disease. Arc. Neurol 2003; 60: 510-515

137. Bu G. Apolipoprotein $E$ and its receptors in alzheimer's disease: pathways pathogenesis and therapy. Nat Rev Neurosci 2009; $10: 333-344$

138. Cirrito JR, May PC, O'Dell MA, et al. In vivo assessment of brain interstitial fluid with microdialysis reveals plaqueassociated changes in amyloid- $\beta$ metabolism and halflife. $J$ Neurosci 2003; 23: 8844-8853.

139. Bateman RJ, Munsell LY, Morris JC, Swarm R, Yarasheski KE, Holtzman DM.. Human amyloid- $\beta$ synthesis and clearance rates as measured in cerebrospinal fluid in vivo. Nature Med. 12, 856-861 (2006).

140. Rebeck GW, ReiterJS, StricklandDK, Hyman BT.Apolipoprotein $\mathrm{E}$ in sporadic Alzheimer's disease: allelic variation and receptor interactions. Neuron 1993; 11: 575-580.

141. Deane R, Wu Z, Sagare A, Davis J, et al. LRP/amyloid $\beta$-peptide interaction mediates differential brain efflux of $A \beta$ isoforms. Neuron 2004; 43: 333-344.

142. Strittmatter WJ, Saunders AM, Schmechel D, et al. Apolipoprotein $\mathrm{E}$ : high-avidity binding to $\beta$-amyloid and increased frequency of type 4 allele in late-onsetAlzheimer disease. Proc Natl Acad Sci USA 1993; 90: 1977-1981.

143. Mahley RW. Apolipoprotein E: cholesterol transport protein with expanding role in cell biology. Science 1988; 240 : $622-630$.

144. Bertram L, Tanzi RE. Thirty years of Alzheimer's disease genetics: the implications of systematic metaanalyses. Nature Rev Neurosci 2008; 9: 768-778.

145. Blacker D, Haines JL, Rodes L, et al. ApoE-4 and age at onset of Alzheimer's disease: the NIMH genetics initiative. Neurology 1997; 48: 139-147.

146. LaDu MJ, Falduto MT, Manelli AM, Reardon CA, Getz GS,
Frail DE. Isoform-specific binding of apolipoprotein $E$ to B-amyloid. J Biol Chem 1994; 269: 23403-23406.

147. Holtzman DM, Bales KR, Wu S, et al. Expression of human apolipoprotein $\mathrm{E}$ reduces amyloid- $\beta$ deposition in a mouse model of Alzheimer's disease. J Clin Invest 1999; 103 : R15-R21.

148. DeMattos RB, Cirrito JR, Parsadanian M, et al. ApoE and clusterin cooperatively suppress $A \beta$ levels and deposition: evidence that $A$ poE regulates extracellular $A \beta$ metabolism in vivo. Neuron 2004; 41: 193-202.

149. Schmechel DE, Saunders AM, Strittmatter WJ, et al. Increased amyloid $\beta$-peptide deposition in cerebral cortex as a consequence of apolipoprotein $\mathrm{E}$ genotype in late-onset Alzheimer disease. Proc Natl Acad Sci USA 1993; 90: 9649-9653.

150. Bogdanovic N, Corder E, Lannfelt L, Winblad B. APoE polymorphism and clinical duration determine regional neuropathology in Swedish $\operatorname{APP}(670,671)$ mutation carriers: implications for late-onset Alzheimer's disease. $J$ Cell Mol Med 2002; 6: 199-214.

151. Small GW, Siddarth $P$, Burggren $A C$, et al. Influence of cognitive status, age, and APoE-4 genetic risk on brain FDDNP positronemission tomography imaging in persons without dementia. Arch Gen Psychiatry 2009; 66: 81-87.

152. Bredesen DE, Rao RV, Mehlen P. Cell death in the nervous system. Nature 2006; 443: $796-802$.

153. Salvesen GS, Dixit VM. Caspases: intracellular signaling by proteolysis. Cell 1997; 91: 443-446.

154. Morishima N, Nakanishi K, Takenouchi H, Shibata T, Yasuhiko Y. An endoplasmic reticulum stress-specific caspase cascade in apoptosis. Cytochrome c-independent activation of caspase- 9 by caspase-12. J Biol Chem 2002; 277: 34287-34294.

155. Rao RV, Castro-Obregon S, Frankowski H, et al. Coupling endoplasmic reticulum stress to the cell death program. An Apaf-1-independent intrinsic pathway. $J$ Biol Chem 2002; 277: 21836-21842.

156. Yuan J, Yankner BA. Caspase activity sows the seeds of neuronal death. Nature Cell Biol 1999; 1: E44-E45.

157. Green DR, Kroemer G. Pharmacological manipulation of cell death: clinical applications in sight? J Clin Invest 2005; 115: $2610-2617$

158. Mizushima N, Levine B, Cuervo AM, Klionsky DJ. Autophagy fights disease through cellular self-digestion. Nature 2008; 451:1069-1075.

159. Lee JA, Gao FB. Regulation of $A \beta$ pathology by beclin 1: a protective role for autophagy? J Clin Invest 2008; 118: 2015.

160. Grimm MO, Grimm HS, Pätzold AJ, et al. Regulation of cholesterol and sphingomyelin metabolism by amyloidbeta and presenilin. Nat Cell Biol 2005; 7: 1118 - 1123.

161. Mattson MP, Cutler RG, Jo DG. Alzheimer peptides perturb lipid - regulating enzymes. Nat Cell Biol 2005; 7 : 1045 1047.

162. Petersen RC. Mild cognitive impairment as a diagnostic entity. J Intern Med 2004; 256: 183 - 194.

163. Blennow K, Zetterberg $\mathrm{H}$. Pinpointing plaques with PIB. Nat Med 2006; 12: 753 - 754 .

164. The Ronald and Nancy Reagan Research Institute of the Alzheimer's Association and the National Institute on Aging Working group. Consensus report of the Working group on "Molecular and biochemical markers of Alzheimer's disease". Neurobiol Aging 1998; 19: 109- 116.

165. Sjögren M, Andreasen N, Blennow K. Advances in the detection of alzheimer's disease - use of cerebrospinal fluid biomarkers. Clin Chim Acta 2003; 332: 1- 10. 
166. Tamaoka A, Sawamura N, Odaka A, et al. Amyloid beta protein 1- 42/43 (A beta 1-42/43) in cerebellar diffuse plaques: enzyme-linked immunosorbent assay and immunocytochemical study. Brain Res 1995; 679: 151156.

167. Goedert M, Wischik CM, Crowther RA, Walker JE, Klug A. Cloning and sequencing of the cDNA encoding a core protein of the paired helical filament of Alzheimer disease identification as the microtubule-associated protein tau. Proc Natl Acad Sci USA1988; 85: 4051- 4055

168. Haass C, Hung AY, Schlossmacher MG, Oltersdorf T, Teplow DB, Selkoe DJ. Normal cellular processing of the betaamyloid precursor protein results in the secretion of the amyloid beta peptide and related molecules. Ann NY Acad Sci 1993; 695: 109-116.

169. Motter R, Vigo Pelfrey C, Kholodenko D, et al. Reduction of beta-amyloid peptide42 in the cerebrospinal fluid of patients with Alzheimer's disease. Ann Neurol 1995; 38 : 643-648.

170. Tamaoka A, Sawamura N, Fukushima T, et al. Amyloid beta protein $42(43)$ in cerebrospinal fluid of patients with Alzheimer's disease. J Neurol Sci 1997; 148: 41- 45.

171. Mehta PD, Pirttila T, Mehta SP, Sersen EA, Aisen PS, Wisniewski HM. Plasma and cerebrospinal fluid levels of amyloid beta proteins $1-40$ and $1-42$ in Alzheimer disease. Arch Neurol 2000; 57: 100- 105.

172. Vanderstichele H, BlennowK, D'Heuvaert N, et al. Development of a specific diagnostic test for measurement of b-amyloid( 1-42) in CSF. In: Fisher A, Hanin I, Yoshida M, editors. Progress in Alzheimer's and Parkinson's diseases. New York: Plenum; 1998. p. 773-778.

173. Andreasen N, Minthon L, Davidsson $P$, et al. Evaluation of CSF-tau and CSF-Abeta42 as diagnostic markers for Alzheimer disease in clinical practice. Arch Neurol 2001; 58: $373-379$

174. Kanemaru K, Kameda N, Yamanouchi H. Decreased CSF amyloid beta42 and normal tau levels in dementia with Lewy bodies. Neurology 2000; 54: 1875- 1876.

175. Hulstaert F, Blennow K, Ivanoiu A, et al. Improved discrimination of $A D$ patients using beta-amyloid $(1-42)$ and tau levels in CSF. Neurology 1999; 52: 1555-1562.

176. Sjogren $M$, Minthon L, Davidsson $P$, et al. CSF levels of tau, beta-amyloid(1-42) and GAP-43 in frontotemporal dementia, other types of dementia and normal aging. $J$ Neural Transm 2000; 107: 563-579.

177. Otto M, Esselman H, Schultz-Schaeffer W, et al. Decreased beta-amyloid1-42 in cerebrospinal fluid of patients with Creutzfeldt- Jacob disease. Neurology 2000; 54: 10991102.

178. Kapaki E, Kilidireas K, Paraskevas GP, Michalopoulou M, Patsouris E. Highly increased CSF tau protein and decreased beta-amyloid (1-42) in sporadic CJD: a discrimination from Alzheimer's disease? J Neurol Neurosurg Psychiatry 2001; 71: 401- 403.

179. Sjogren M, Davidsson $P$, Wallin A, et al. Decreased CSF-[beta]amyloid 42 in Alzheimer's disease and amyotrophic lateral sclerosis may reflect mismetabolism of [beta]-amyloid induced by disparate mechanisms. Dement Geriatr Cogn Disord 2002; 13: 112- 118.

180. Ichihara $\mathrm{N}$, Wu J, Chui $\mathrm{DH}$, Yamazaki K, Wakabayashi T, Kikuchi T. Axonal degeneration promotes abnormal accumulation of amyloid beta-protein in ascending gracile tract of gracile axonal dystrophy (GAD) mouse. Brain Res 1995; 695: 173-178.

181. Sjogren M, Gisslen M, Vanmechelen $E$, Blennow $K$. Low cerebrospinal fluid beta-amyloid 42 in patients with acute bacterial meningitis and normalization after treatment. Neurosci Lett 2001; 314: 33- 36.
182. Goedert M. Tau protein and the neurofibrillary pathology of Alzheimer's disease. Trends Neurosci 1993; 16: 460465.

183. Vandermeeren $M$, Mercken $M$, Vanmechelen $E$, et al. Detection of tau proteins in normal and Alzheimer's disease cerebrospinal fluid with a sensitive sandwich enzymelinked immunosorbent assay. J Neurochem 1993; 61: 1828- 1834

184. Blennow K, Wallin A, Agren $\mathrm{H}$, Spenger C, Siegfried J, Vanmechelen $\mathrm{E}$. Tau protein in cerebrospinal fluid: a biochemical marker for axonal degeneration in Alzheimer disease? Mol Chem Neuropathol 1995; 26: 231- 245.

185. Vigo-Pelfrey C, Seubert P, Barbour R, et al. Elevation of microtubule-associated protein tau in the cerebrospinal fluid of patients with Alzheimer's disease. Neurology 1995; 45: 788-793.

186. Green AJ, Harvey RJ, Thompson EJ, Rossor MN. Increased tau in the cerebrospinal fluid of patients with frontotemporal dementia and Alzheimer's disease. Neurosci Lett 1999; 259: 133-135.

187. Molina L, Touchon J, Herpe M, et al. Tau and apo E in CSF: potential aid for discriminating Alzheimer's disease from other dementias. Neuroreport 1999; 10: 3491-3495

188. Morikawa $\mathrm{Y}$, Arai $\mathrm{H}$, Matsushita $\mathrm{S}$, et al. Cerebrospinal fluid tau protein levels in demented and nondemented alcoholics. Alcohol Clin Exp Res 1999; 23: 575- 577.

189. Urakami K, Mori M, Wada K, et al. A comparison of tau protein in cerebrospinal fluid between corticobasal degeneration and progressive supranuclear palsy. Neurosci Lett 1999; 259: $127-129$.

190. Hesse C, Rosengren L, Vanmechelen E, et al. Cerebrospinal fluid markers for Alzheimer's disease evaluated after acute ischemic stroke. J Alzheimer's Dis 2000; 2:199- 206.

191. Otto M, Wiltfang J, Tumani $\mathrm{H}$, et al. Elevated levels of tauprotein in cerebrospinal fluid of patients with Creutzfeldt -Jakob disease. Neurosci Lett 1997; 225: 210-212.

192. Tapiola T, Overmyer M, Lehtovirta M, et al. The level of cerebrospinal fluid tau correlates with neurofibrillary tangles in Alzheimer's disease. Neuroreport 1997; 8: 3961- 3963.

193. Sjogren M, Davidsson P, Gottfries J, et al. The cerebrospinal fluid levels of tau, growth-associated protein-43 and soluble amyloid precursor protein correlate in Alzheimer's disease, reflecting a common pathophysiological process. Dement Geriatr Cogn Disord 2001; 12: 257-264.

194. Ferreira A, Busciglio J, Caceres A. Microtubule formation and neurite growth in cerebellar macroneurons which develop in vitro: evidence for the involvement of the microtubuleassociated proteins, MAP-1a, HMW-MAP2 and Tau. Brain Res Dev Brain Res 1989; 49: 215- 228.

195. IqbalK, Grundke-lqbal I. Mechanism of Alzheimer neurofibrillary degeneration and the formation of tangles. Mol Psychiatry 1997; 2: 178- 180.

196. Geddes JW, Tekirian TL, Soultanian NS, Ashford JW, Davis DG, Markesbery WR. Comparison of neuropathologic criteria for the diagnosis of Alzheimer's disease. Neurobiol Aging 1997; 18: S99-S105.

197. Vanmechelen $E$, Vanderstichele $H$, Davidsson $P$, et al Quantification of tau phosphorylated at threonine 181 in human cerebrospinal fluid: a sandwich ELISA with a synthetic phosphopeptide for standardization. Neurosci Lett 2000; 285: 49-52.

198. Ishiguro $\mathrm{K}, \mathrm{Ohno} \mathrm{H}$, Arai $\mathrm{H}$, et al. Phosphorylated tau in human cerebrospinal fluid is a diagnostic marker for Alzheimer's disease. Neurosci Lett 1999; 270: 91-94.

199. Kohnken R, Buerger K, Zinkowski R, et al. Detection of tau phosphorylated at threonine 231 in cerebrospinal fluid of 
Alzheimer's disease patients. Neurosci Lett 2000; 287 : 187- 190.

200. Hu YY, He SS, Wang X, et al. Levels of nonphosphorylated and phosphorylated tau in cerebrospinal fluid of Alzheimer's disease patients: an ultrasensitive bienzyme-substraterecycle enzyme-linked immunosorbent assay. Am J Pathol 2002; 160: 1269- 1278.

201. Sjogren $M$, Davidsson $P$, Tullberg $M$, et al. Both total and phosphorylated tau are increased in Alzheimer's disease. J Neurol Neurosurg Psychiatry 2001; 70: 624-630.

202. Parnetti L, Lanari A, Amici S, Gallai V, Vanmechelen E, Hulstaert F. CSF phosphorylated tau is a possible marker for discriminating Alzheimer's disease from dementia with Lewy bodies. Phospho-Tau International Study Group. Neurol Sci 2001; 22: 77- 78.

203. Hesse C, Rosengren L, Andreasen N, et al. Transient increase in total tau but not phospho-tau in human cerebrospinal fluid after acute stroke. Neurosci Lett 2001;297:18790. Hulstaert F, Blennow K, Ivanoiu A, et al. Improved discrimination of $A D$ patients using beta-amyloid(1 - 42) and tau levels in CSF. Neurology 1999; 52: 1555-1562.

204. Galasko D, Chang L, Motter R, et al. High cerebrospinal fluid tau and low amyloid beta42 levels in the clinical diagnosis of Alzheimer disease and relation to apolipoprotein $\mathrm{E}$ genotype. Arch Neurol 1998; 55: 937- 945.

205. Kanai M, Matsubara E, Isoe K, et al. Longitudinal study of cerebrospinal fluid levels of tau, A beta1- 40 , and A beta1-42(43) in Alzheimer's disease: a study in Japan. Ann Neurol 1998; 44: 17- 26.

206. Andreasen N, Minthon L, Vanmechelen E, et al. Cerebrospinal fluid tau and Abeta42 as predictors of development of Alzheimer's disease in patients with mild cognitive impairment. Neurosci Lett 1999; 273: 5-8.

207. Kurz A, Riemenschneider M, Buch K, et al. Tau protein in cerebrospinal fluid is significantly increased at the earliest clinical stage of Alzheimer disease. Alzheimer Dis Assoc Disord 1998; 12: 372-377.

208. Riemenschneider M, Buch K, Schmolke M, KurzA, Guder WG. Cerebrospinal protein tau is elevated in early Alzheimer's disease. Neurosci Lett 1996; 212: 209-211.

209. Riemenschneider M, Schmolke $M$, Lautenschlager $N$, et al. Cerebrospinal beta-amyloid $(1-42)$ in early Alzheimer's disease: association with apolipoprotein $\mathrm{E}$ genotype and cognitive decline. Neurosci Lett 2000; 284: 85- 88.

210. Arai $\mathrm{H}$, Ishiguro $\mathrm{K}$, Ohno $\mathrm{H}$, et al. CSF phosphorylated tau protein and mild cognitive impairment: a prospective study. Exp Neurol 2000; 166: 201-203.

211. Buerger K, Teipel SJ, Zinkowski R, et al. CSF tau protein phosphorylated at threonine 231 correlates with cognitive decline in $\mathrm{MCl}$ subjects. Neurology 2002; 59: 627-629.

212. Olsson $A$, Vanderstichele $H$, Andreasen $N$, et al. Simultaneous measurement of $\beta$-Amyloid (1-42), total tau, and phosphorylated tau (Thr181) in cerebrospinal fluid by the xMAP technology. Clin Chem 2005; 51: 336 - 345.

213. LaFerla FM, Oddo S. Alzheimer's disease: Abeta, tau and synaptic dysfunction. Trends Mol Med 2005; 11: 170 176.

214. Lee MJ, Blennow K, Andreasen N, et al. The Brain injury biomarker VLP-1 is increased in the cerebrospinal fluid of Alzheimer disease patients. Clin Chem 2008; 54: 1617 1623.

215. Zhao C, Braunewell $\mathrm{KH}$. Expression of the neuronal calcium sensor visininlike protein-1 in the rat hippocampus. Neuroscience 2008; 153: 1202-1212.

216. Braunewell K, Riederer P, Spilker C, Gundelfinger ED, Bogerts B, Bernstein HG. Abnormal localization of two neuronal calcium sensor proteins, visininlike proteins (vilips)-1 and
-3 , in neocortical brain areas of Alzheimer disease patients. Dement Geriatr Cogn Disord 2001; 12: 110-116.

217. Schnurra I, Bernstein HG, Riederer P, Braunewell KH. The neuronal calcium sensor protein VILIP-1 is associated with amyloid plaques and extracellular tangles in Alzheimer's disease and promotes cell death and tau phosphorylation in vitro: a link between calcium sensors and Alzheimer's disease? Neurobiol Dis 2001; 8: 900 -909.

218. Laterza OF, Modur VR, Crimmins DL, Olander JV, Landt Y, Lee $\mathrm{JM}$, Ladenson $\mathrm{JH}$. Identification of novel brain biomarkers. Clin Chem 2006; 52: 1713-1721.

219. de Jong D, Kremer BP, Olde Rikkert MG, Verbeek MM. Current state and future directions of neurochemical biomarkers for Alzheimer's disease. Clin Chem Lab Med 2007; 45: 1421-1434.

220. Verbeek MM, de Jong D, Kremer HPH. Brain-specific proteins in cerebrospinal fluid for the diagnosis of neurodegenerative diseases. Ann Clin Biochem 2003; 40: 25- 40.

221. Verbeek MM, Olde Rlkkert MGM. Cerebrospinal fluid biomarkers in the evaluation pf Alzheimer disease. Clin Chem 2008; 54: 1589 - 1591.

222. Dubois B, Feldman HH, Jacova C, DeKosky ST, BarbergerGateau $P$, Cummings J, et al. Research criteria for the diagnosis of Alzheimer's disease: revising the NINCDSADRDA criteria. Lancet Neurol 2007; 6: 734-746.

223. Blennow K, Wallin A, Ekman R. Neuron specific enolase in cerebrospinal fluid: a biochemical marker for neuronal degeneration in dementia disorders? J Neural Transm Park Dis Dement Sect 1994; 8: 183-191.

224. Parnetti L, Palumbo B, Cardinali L, Loreti F, Chionne F, Cecchetti R, Senin U. Cerebrospinal fluid neuron-specific enolase in Alzheimer's disease and vascular dementia. Neurosci Lett 1995; 183: 43-45.

225. Peskind ER, Griffin WS, Akama KT, Raskind MA, Van Eldik LJ. Cerebrospinal fluid S100B is elevated in the earlier stages of Alzheimer's disease. Neurochem Int 2001; 39: $409-413$.

226. Fukuyama R, Izumoto T, Fushiki S. The cerebrospinal fluid level of glial fibrillary acidic protein is increased in cerebrospinal fluid from Alzheimer's disease patients and correlates with severity of dementia. Eur Neurol 2001; 46:3 5- 38.

227. Finehout EJ, Franck Z, Relkin N, Lee KH. Proteomic analysis of cerebrospinal fluid changes related to postmortem interval. Clin Chem 2006; 52: 1906 -1913.

228. Lescuyer P, Allard L, Zimmermann-Ivol CG, Burgess JA, Hughes-Frutiger S, Burkhard PR, et al. Identification of post-mortem cerebrospinal fluid proteins as potential biomarkers of ischemia and neurodegeneration. Proteomics 2004; 4: 2234-2241.

229. Zimmermann-Ivol CG, Burkhard PR, Le Floch-Rohr J, Allard L, Hochstrasser DF, Sanchez JC. Fatty acid binding protein as a serum marker for the early diagnosis of stroke: a pilot study. Mol Cell Proteomics 2004; 3: $66-72$.

230. Allard L, Burkhard PR, Lescuyer P, Burgess JA, Walter N, Hochstrasser DF, Sanchez JC. PARK7 and nucleoside diphosphate kinase $\mathrm{A}$ as plasma markers for the early diagnosis of stroke. Clin Chem 2005; 51: 2043-2051.

231. Saunders AM, Strittmatter WJ, Schmechel D, George-Hyslop $\mathrm{PH}$, Pericak-Vance MA, Joo $\mathrm{SH}$, et al. Association of apolipoprotein $\mathrm{E}$ allele epsilon 4 with late-onset familial and sporadic Alzheimer's disease. Neurology 1993; 43: 1467-1472.

232. Biere AL, Ostaszewski B, Stimson ER, Hyman BT, Maggio JE, Selkoe DJ. Amyloid beta-peptide is transported on lipoproteins and albumin in human plasma. $J \mathrm{Biol}$ Chem 1996; 271: 32916 -32922.

233. Horsburgh $K$, McCulloch J, Nilsen $M$, Roses AD, Nicoll JA. 
Increased neuronal damage and apoE immunoreactivity in human apolipoprotein E, E4 isoform-specific, transgenic mice after global cerebral ischaemia. Eur J Neurosci 2000; 12: 4309-4317.

234. Steinman L. Elaborate interactions between the immune and nervous systems. Nat Immunol 2004; 5: $575-581$.

235. Ray S, Britschgi M, Herbert $C$, et al. Classification and prediction of clinical alzheimer's diagnosis based on plasma signaling proteins. Nat Med 2007; 13: 1359 1362.

236. Simard AR, Soulet D, Gowing G, Julien JP, Rivest S. Bone marrow-derived microglia play a critical role in restricting senile plaque formation in Alzheimer's disease. Neuron 2006; 49: 489 - 502 .

237. Britschgi M, Wyss-Coray T. Systemic and acquired immune responses in Alzheimer's disease. Int Rev Neurobioli 2007; 82: $205-233$.

238. LeBlanc AC. The role of apoptotic pathways in Alzheimer's disease neurodegeneration and cell death. Curr Alzheimer Res 2005; 2: 389-402.

239. Rollins G. The search for alzheimer's diagnostics. Are they close or still years away? Clin Lab News 2009; 35: 1-4. 